\title{
Perception of effort and the allocation of physical resources: a generalization to upper-limb motor tasks
}

5 Payen de la Garanderie Marie ${ }^{1,2}$, Courtay Aymeric ${ }^{1,2,3}$, Féral-Basin Camille ${ }^{1,2}$, Rainville Pierre ${ }^{2,4}$,

6 Gaveau Jérémie ${ }^{3,5}$, and Pageaux Benjamin ${ }^{1,2 *}$

$8{ }^{1}$ École de Kinésiologie et des Sciences de l'Activité Physique (EKSAP), Faculté de médecine, 9 Université de Montréal, Canada.

$10{ }^{2}$ Centre de Recherche de l'Institut Universitaire de Gériatrie de Montréal (CRIUGM), Canada.

$11{ }^{3}$ INSERM UMR1093-CAPS, Université Bourgogne Franche-Comté, UFR des Sciences du Sport, 12 Dijon, France.

$13{ }^{4}$ Département de Stomatologie, Faculté de médecine dentaire, Université de Montréal, Canada.

$14{ }^{5}$ Espace d'Etude du Mouvement-Etienne Jules MAREY, Université Bourgogne Franche-Comte, 15 UFR des Sciences du Sport, F-21000 Dijon, France.

\section{*Correspondence to:}

18 Benjamin Pageaux

19 CEPSUM, École de kinésiologie,

20 2100, boulevard Édouard-Montpetit,

21 Montréal, Québec,

22 H3T $1 \mathrm{~J} 4$

23 Canada

24 benjamin.pageaux@umontreal.ca

All authors have agreed to submission to SportRxiv

\section{Citation :}

30 Payen de la Garanderie, M., Courtay, A., Féral-Basin, C., Rainville, P., Gaveau, J., \& Pageaux, B. 31 (2021). Perception of effort and the allocation of physical resources: a generalization to upper-limb 32 motor tasks. SportRxiv. https://doi.org/10.31236/osf.io/2ehtb 


\section{Abstract}

34 Purpose: The perception of effort (PE) is widely used to prescribe and monitor exercise during 35 locomotor and resistance tasks. The present study examines the validity of PE to prescribe and monitor 36 exercise during upper-limb motor tasks under various loads and speed requirements.

37 Methods: Forty participants volunteered in two experiments. In experiment 1, we used four PE 38 intensities to prescribe exercise on a modified version of the box and block test (BBT) and a pointing 39 task. We investigated the possibility of monitoring the exercise intensity by tracking changes in PE 40 rating in response to three different tempos or additional weights. Experiment 2 replicated the 41 possibility of prescribing the exercise with the PE intensity during the BBT and explored the impact of 42 additional weights on performance and PE during the standardized version of the BBT. Muscle 43 activation, heart rate and respiratory frequencies were recorded.

44 Results: In experiment 1, increasing the PE intensity to prescribe exercise induced an increased performance between each intensity. Increasing task difficulty with faster movement tempo and adding weight on the forearm increased the rating of PE. Experiment 2 replicated the possibility to use PE intensity for exercise prescription during the BBT. When completing the BBT with an additional weight on the forearm, participants maintained performance at the cost of a higher PE. In both experiments, changes in PE are associated with changes in muscle activation.

Conclusion: Our results suggest that $\mathrm{PE}$ is a valid tool to prescribe and monitor exercise during upper51 limb motor tasks.

246 words

Keywords: perceived exertion, upper-limb task, CR100 scale, motor control, psychophysiology, Box and Block Test, Pointing Task. (Min.5-Max. 8) 


\section{Introduction}

The perception of effort, also known as perceived exertion or sense of effort (Marcora, 2010; Pageaux, 2016), can be described as "the particular feeling of that energy being exerted", and "is accompanied by a sensation of strain and labour, a feeling that intensifies the harder a person tries" (Preston \& Wegner, 2009). Effort is experienced during physical (e.g., running to catch the bus) or cognitive tasks (e.g., completing Sudoku) and in the context of self-restraint behaviour (e.g smoking cessation ; Preston, 2009). It is thought to influence how we move, i.e., how the nervous system selects a given movement amongst a myriad of possibilities (Gaveau et al., 2021; Izawa et al., 2008). Due to its omnipresence in our daily life, the interest in understanding perception of effort is growing amongst researchers. This perception is linked to the task intensity and the amount of resources invested (Inzlicht et al., 2018); strongly influences the self-regulation of human behaviour (Inzlicht et al., 2018; Marcora, 2015); is one of the main features of fatigue in various contexts (Enoka \& Stuart, 1992; Pageaux \& Lepers, 2016); and is exacerbated in various pathologies such as chronic fatigue syndrome (Barhorst et al., 2020; Cook et al., 2007), stroke (Kuppuswamy et al., 2015), chronic kidney disease (Macdonald et al., 2012) or cancer (Fernandez et al., 2020). Perception of effort is a fundamental experience that directly influences our everyday decisions to engage or disengage in various actions, by monitoring the cognitive and motor resources necessary to perform any task (Pageaux, 2016; Preston, 2009). The perception of the amount of effort invested in a task is also closely linked to the regulation of motor performance (Marcora, 2019; Pageaux, 2014, 2016). According to the motivation intensity theory (Brehm \& Self, 1989; Richter et al., 2016), one maintains performance by increasing effort when task difficulty increases, and one lets performance decrease when no longer able or willing to invest additional effort.

Perception of effort is widely investigated during global locomotor tasks, such as walking or cycling, in both healthy and symptomatic populations (Au et al., 2017; Décombe et al., 2020; Flairty \& Scheadler, 2020; Horstman et al., 1979; Zinoubi et al., 2018) to prescribe and monitor exercise (Azevedo et al., 2016; Eston \& Parfitt, 2018; Impellizzeri et al., 2004). Perception of effort is also investigated during isolated motor tasks involving the upper or lower limb, in strength training program (Miller et al., 2009; Zourdos et al., 2016), in studies aiming at better understanding the regulation of endurance performance (Maikala \& Bhambhani, 2006; Pageaux et al., 2013) or the mechanisms associated with the development of muscle fatigue during repetitive tasks (de Morree et al., 2012; Jacquet et al., 2021; Otto et al., 2019; Yang et al., 2019). To the best of our knowledge, most of the 
studies investigating perception of effort are performed during locomotor exercises or isolated exercises performed with the lower limbs (de Morree et al., 2014; Faelli et al., 2019; Luu et al., 2016; Meir et al., 2015). Although perception of effort is of interest to understand how the nervous system controls our everyday movements, motor control studies have mostly indirectly investigated it by measuring the force output, the decision made by the participants, or motor strategies (Cos, 2017; Gaveau et al., 2021; Izawa \& Shadmehr, 2008; Morel et al., 2017; Shadmehr et al., 2016; Wang et al., 2021). While these methods present several advantages in the context of decision-making tasks, not considering the rating of perception of effort as a dependant variable limits the exploration of the subjective experience of the participant during task completion (Pageaux, 2016; Wang et al., 2021). As the perception of effort has been recently proposed to finely regulate motor control (Cos, 2017) and thus, to affect decision-making and performance in a task involving movement regulation (Shadmehr et al., 2016; Wang et al., 2021), there is an urgent need for studies exploring the perception of effort during upper limb tasks. Such studies could provide opportunities to better understand the interaction between perception of effort and motor control.

In this context, the present study aimed to validate the use of the perception of effort to prescribe and monitor exercise in healthy young adults performing upper limb motor tasks. To do so, two experiments manipulated the physical demand to alter the task difficulty. In the first experiment, by using a modified version of the classical box and block test (Mathiowetz, 1985) and a pointing task, we tested the possibility i) to prescribe exercise at different intensities with the perception of effort and ii) to monitor changes in perception of effort when task difficulty was altered with manipulation of the physical demand. As effort and its perception vary in relation to performance (Brehm \& Self, 1989; Richter et al., 2016), we monitored perception of effort while controlling for performance. We hypothesized that i) it is possible to prescribe different exercise intensities with the perception of effort, as attested by an increased task performance when the prescribed intensity of perceived effort increases; and ii) that increasing task difficulty, with faster tempos or additional weights, will be reflected in higher perceptions of effort. In the second experiment, by using the classical box and block test with its validated instructions, we tested the effect of increasing physical demand on subsequent performance and rating of perception of effort. We hypothesized that performance could be maintained at the cost of a higher resource mobilization as reflected by the increases in the perception of effort. 


\section{Materials and methods}

121

122

123

\section{Table 1. Description of participants}

133

Yrs = years, $\mathrm{kg}=$ kilogram, $\mathrm{cm}=$ centimeter. The physical activity score was measured with the 135
Experiment 1

\begin{tabular}{ccccc}
\cline { 2 - 4 } & $\begin{array}{c}\text { Women } \\
(\mathrm{n}=18)\end{array}$ & $\begin{array}{c}\text { Men } \\
(\mathrm{n}=2)\end{array}$ & $\begin{array}{c}\text { Women } \\
(\mathrm{n}=7)\end{array}$ & $\begin{array}{c}\text { Men } \\
(\mathrm{n}=13)\end{array}$ \\
\hline Age $(\mathrm{yrs})$ & $24 \pm 2$ & $24 \pm 2$ & $26 \pm 2$ & $25 \pm 2$ \\
\hline Weight $(\mathrm{kg})$ & $62 \pm 11$ & $72 \pm 14$ & $59 \pm 7$ & $76 \pm 10$ \\
\hline Height $(\mathrm{cm})$ & $164 \pm 10$ & $187 \pm 5$ & $163 \pm 6$ & $178 \pm 5.4$ \\
\hline Physical activity $(/ 30)$ & $19.06 \pm 5.4$ & $23 \pm 0$ & $21.5 \pm 6.3$ & $23.6 \pm 3.5$ \\
\hline Right-handed & 17 & 2 & 7 & 2 \\
\hline Left-handed & 1 & - & - & 11 \\
\hline
\end{tabular}

Experiment 2 


\section{Upper limb motor tasks}

In this study, the upper limb motor tasks were the Box and Block Test (BBT) and a Pointing Task

140 (PT). A full description of these tests is available below. We chose these two tests for their relevance 141 in the context of clinical settings as well as research.

\section{a. Box and Block test}

143 The BBT (Mathiowetz, 1985), illustrated in Figure 1A, is used to assess manual dexterity, 144 defined as "the ability to make coordinated hand and finger movements to grasp and manipulate 145 objects" (Makofske, 2011). This test has been validated in several populations such as older adults 146 (Desrosiers et al., 1994), fibromyalgia patients (Canny et al., 2009) and stroke rehabilitation (Lin et al., 147 2010). The test consists of a wooden box $(53.7 \mathrm{~cm} \times 25.4 \mathrm{~cm} \times 8.5 \mathrm{~cm})$ separated into two containers 148 of $25.4 \mathrm{~cm}$ each. It includes 150 wooden cubes $(2.5 \mathrm{~cm})$. Participants have to grasp one block at a time 149 with the dominant hand, transport the block over the partition, and release it into the opposite 150 compartment. Standardized instructions require participants to move as many blocks as possible in 60 $151 \mathrm{~s}$, and performance is monitored as the number of blocks moved. In experiment 1, we used a $30 \mathrm{~s}$ modified version of the BBT where participants had to move the blocks at a prescribed effort intensity or by following a pre-determined tempo signaled by an auditory cue to control for the number of blocks moved (performance). In experiment 2, we used the standardized instructions in the absence and presence of additional weight on the dominant forearm. In both experiments, the compartment containing the block was placed in front of the participants' dominant hand. Errors were visually counted by an experimenter when the fingertips did not go beyond the partition, and the associated block was not counted in the final score.

\section{b. Pointing task}

$160 \quad$ Pointing tasks (PT) are widely used in research to study motor control (e.g., Domkin et al., 2002; Missenard et al., 2009). A PT (illustrated in figure 1B) was performed in experiment 1.Participants had

162 to go back and forth between targets (squares of $1 \mathrm{~cm}^{2}$ ) as quickly as possible in a given time. 163 Participants started from target 1 (reference target) and had to follow a pre-determined order, depending on their dominant hand. Right-handed participants had to reach target 2 and come back to target 1 , then reach target 3 and come back to target 1 , then reach target 4 and come back to target 1 , then reach target 5 and come back to target 1 . This sequence was repeated for $30 \mathrm{~s}$, either with the 
167

168

169

170

171

172

173

174

175

176

177

178

179

180

181

182

183

184

185 over the partition, and release it into the opposite compartment. targets $1-3$ and $1-4$ is $21 \mathrm{~cm}$, respectively.

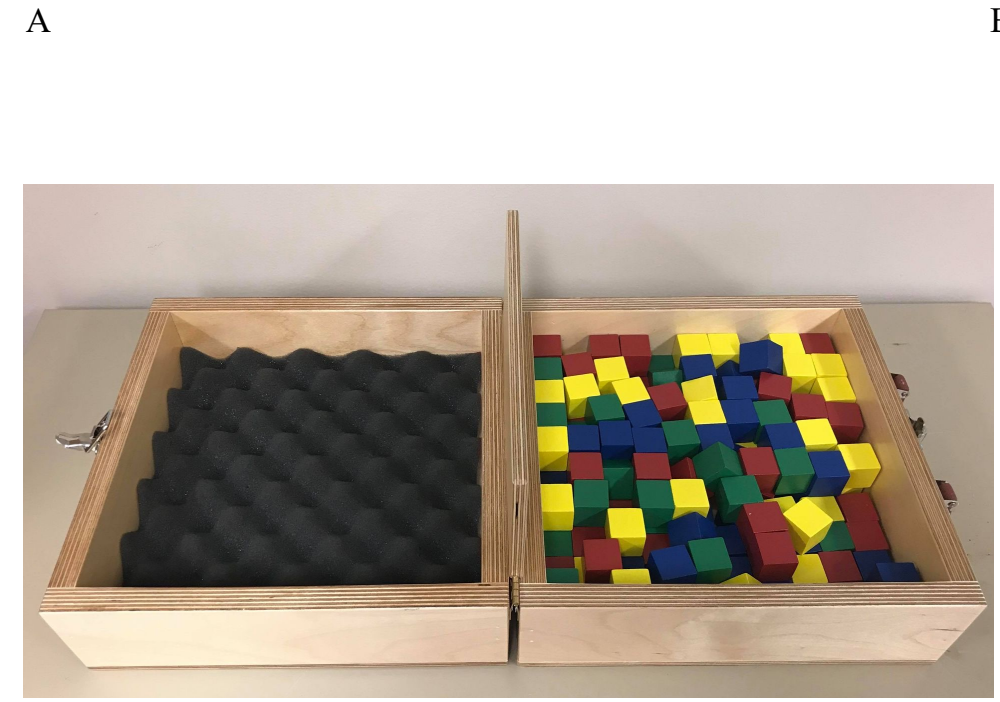

instructions of reaching the targets at a prescribed effort intensity or by following a pre-determined tempo to control for the number of targets reached (i.e., performance). For left-handed participants, the order of the sequence was reversed. They had to first reach target 5. Participants performed the test with a pencil in their hand and had to point where they reached, thus allowing an experimenter to visually control for the exact number of targets correctly reached.

B

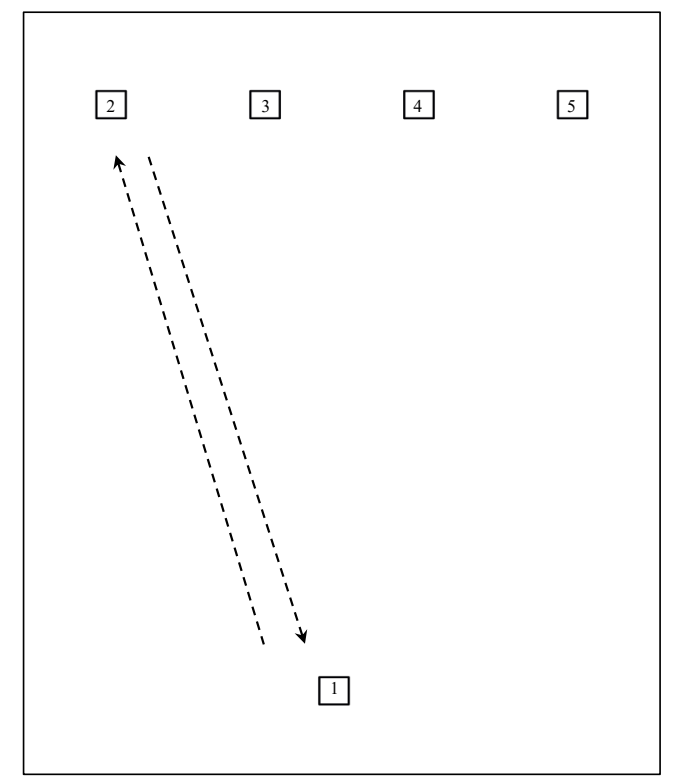

Figure 1. Panel A: Illustration of the Box and Block Test (Mathiowetz, 1985) used in experiments 1 and 2. Briefly, participants had to grasp one block at a time with the dominant hand, transport the block

Panel B: Illustration of the Pointing Task used in experiment 1. Starting from target 1, participants had to go back and forth between each target. Right-handed participants started by reaching target 2 for their first-round trip, while left-handed participants started by reaching target 5 for their first-round trip. Measures are being taken from the center of all squares $(1 \times 1 \mathrm{~cm})$. The distance between each upper square is $5.1 \mathrm{~cm}$. Distance between targets $1-2$ and $1-5$ is $22.3 \mathrm{~cm}$, respectively. Distance between 


\section{Overview of the two experiments}

\section{a. Experiment 1}

This experiment aimed to test, with a modified version of the BBT and a PT, the possibility i) to use the perception of effort to prescribe exercise (Exp. 1A), and ii) to monitor changes in the rating of perception of effort when performance is controlled and task difficulty manipulated (Exp. 1B). i) To test the possibility of prescribing exercise with a target level of perceived effort, we monitored performance associated with four intensities of perception of effort (presented in fig. 2A) ii) To test the possibility of monitoring changes in the perception of effort, we manipulated task difficulty by increasing physical demand. Task difficulty was increased by increasing the speed of movement (tempo session) or by adding a weight on the forearm (weight session). The weight session was performed at a controlled paced such that the effect of task demand on PE was assessed at a controlled performance level (i.e. constant speed). The tempo session and weight session were performed in two different laboratory visits, in a randomized order. An overview of the sessions is presented in figure $2 \mathrm{~B}$. All tests were performed in a seated position. At the onset of the first laboratory visit, participants completed several questionnaires allowing the characterization of the population studied (anthropometry, physical activity score; Robert et al., 2004), Edinburgh Handedness Inventory (Oldfield, 1971). Then, each session was performed as described below, with all BBT trials performed in one block and all PT trials related performed in another block. The order of each block (BBT performed first vs PT performed first) was randomized between participants and kept constant for each participant between the two laboratory visits (tempo session vs weight session).

Tempo session. Participants were equipped with the apparatus allowing measurement of EMG, heart rate and/or respiratory frequency. We subsequently provided standardized instructions on how to use the psychophysical rating scale to monitor the perception of effort and how to perform the BBT and the PT. Participants had 1 min to familiarize themselves with each test and could ask any questions. Following this familiarization, participants were asked to perform a block of trials for the BBT or PT. The first block consisted of trials using a target level of PE intensity to prescribe the exercise, and the second block consisted of trials where performance was controlled by different tempos and where perception of effort was reported by the participant. Trials related to the use of PE to prescribe the exercise intensity consisted of performing one test of $30 \mathrm{~s}$ per target PE intensity level (light effort, moderate effort, strong effort and very strong effort), with each test interspaced by $30 \mathrm{~s}$ of recovery. The experimenter recorded performance for each prescribed intensity. Then, participants performed 
217 two tests of $30 \mathrm{~s}$ per difficulty level (low, moderate, high), with each test interspaced by $90 \mathrm{~s}$ of 218 recovery. Once a block (BBT vs PT trials) was completed, a 120 s rest was given, and participants

219 completed the other block following the same structure. Following pilot experiments, three tempos 220 specific to each task were chosen to produce three levels of difficulties. For the PT, the following 221 tempos were used: $1 \mathrm{~Hz}$ (slow tempo), $1.5 \mathrm{~Hz}$ (moderate tempo) and $2 \mathrm{~Hz}$ (fast tempo). For the BBT, 222 the following tempos were used: $0.5 \mathrm{~Hz}$ (slow tempo), $0.75 \mathrm{~Hz}$ (moderate tempo) and $1 \mathrm{~Hz}$ (fast tempo). 223 The order of level of difficulties was randomized. The rating of perceived effort was measured 224 immediately at the end of each repetition. Following the two repetitions of each difficulty level, 225 participants reported their perceived workload using the NASA TLX scale as described below.

226 Weight session. The procedures in the weight sessions are identical to the procedures in the tempo session, except that task difficulty was manipulated by adding weights (4-lb pair, Enhance Fitness) on the dominant forearm of the participant while performing the BBT and PT at a fixed tempo (BBT: 0.75 Hz; PT: $1.5 \mathrm{~Hz}$ ). The low difficulty level was performed with no additional weight (0 kg, light weight) on the forearm. The moderate and high difficulty levels were performed with additional weights, 0.5 $\mathrm{kg}$ (moderate weight) and $1 \mathrm{~kg}$ (heavy weight) respectively, on the forearm.

\section{b. Experiment 2}

The second experiment aimed (Exp. 2A) to replicate the results of the PE prescription condition of experiment $1 \mathrm{~A}$ and to test the effect of increasing physical demand to manipulate BBT difficulty on subsequent performance and ratings of perception of effort (Exp. 2B). Participants visited the laboratory once. At their arrival, participants were equipped with the apparatus allowing measurement of EMG and heart rate. We subsequently provided standardized instructions on how to use the psychophysical scale to monitor the perception of effort and how to perform the BBT. Participants had 1 min to familiarize themselves with each test and could ask any questions. Following this familiarization, participants were asked to perform two blocks of trials. The first block consisted of trials related to using the perception of effort intensity to prescribe the exercise, as performed in experiment 1. In the second block of trials, participants completed the BBT according to the standardized duration of $60 \mathrm{~s}$, in the absence $(0 \mathrm{~kg}$, low difficulty level) and the presence $(0.5 \mathrm{~kg}$, high difficulty level) of an additional weight on the dominant forearm, interspaced by a 2.5 min recovery between difficulties. The order of difficulty levels $(0 \mathrm{~kg}$, low difficulty level vs $0.5 \mathrm{~kg}$, high difficulty level) was randomized between participants and repeated after a 15 min break. In total, each participant repeated each level of difficulty twice. 
248 Pilot experiments revealed that the duration of $60 \mathrm{~s}$ with an additional weight of $1 \mathrm{~kg}$ induced an 249 important level of fatigue to the participants. Consequently, to limit the induction of fatigue, the high 250 level of difficulty was performed with a weight of $0.5 \mathrm{~kg}$ and a between level of difficulty recovery 251 period of $2.5 \mathrm{~min}$. The rating of perceived effort and performance (i.e., number of blocks moved) was 252 monitored immediately at the end of each repetition (3 repetitions per level of difficulty, with the order 253 of difficulty randomized). Following each level of difficulty, participants reported their perceived 254 workload using the NASA TLX scale as described below. An overview of the session is presented in 255 figure $2 \mathrm{C}$.

\section{A. Experiment 1A and 2A : Prescribing exercise with perception of effort}

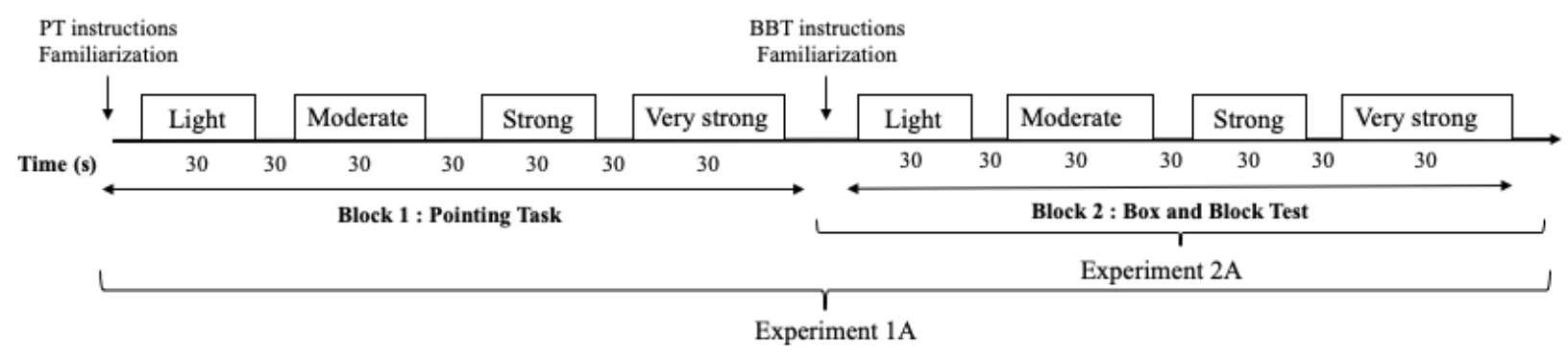

B. Experiment 1B : weight or tempo session

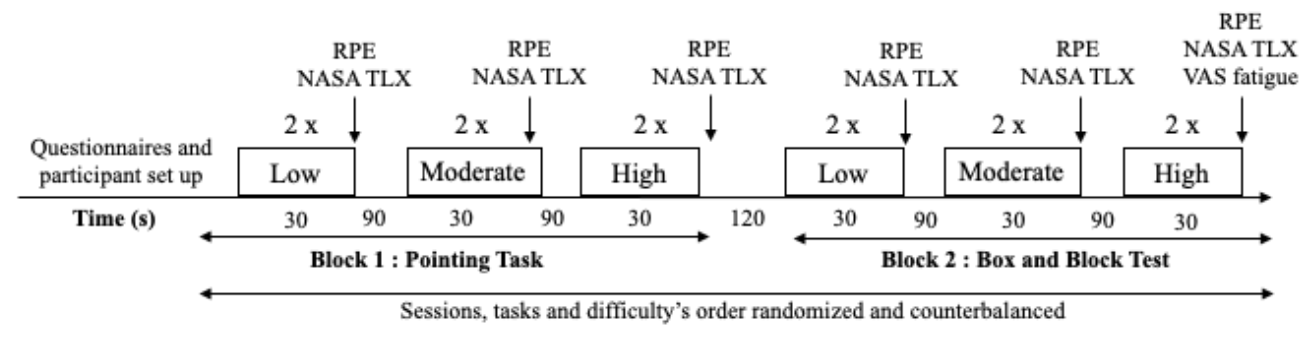

C. Experiment 2B : weight manipulation during the Box and Block Test with its offical instructions

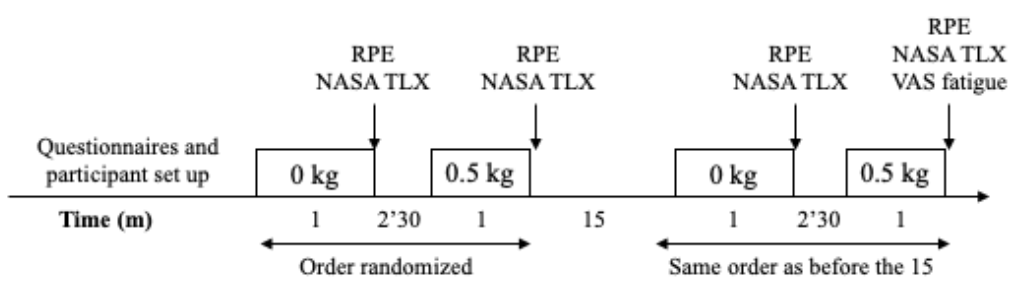

Figure 2. Panel A: Experiments 1A and 2A overview : the procedures used to test the possibility to prescribe exercise using the perception of effort.

The exercise was prescribed at four intensities of perceived effort via the CR100 scale: light (13/100), moderate $(23 / 100)$, strong $(50 / 100)$, very strong $(70 / 100)$. While both the pointing task (PT) and the 
261 Box and Block Test (BBT) were performed in experiment 1A, only the BBT was performed in 262 experiment $2 \mathrm{~A}$.

263 Panel B: Experiment 1B overview. Set up consisted of the placement of the respiratory frequency belt, heart rate monitor and the EMG surface electrodes. Then participants completed the indicated questionnaire or Visual Analog Scale (VAS). Participants performed two repetitions per level of difficulty with $30 \mathrm{~s}$ of recovery in between. Rating of Perceived Effort (RPE) and subjective workload using NASA TLX scale were assessed in-between each level of difficulty.

Panel C: Experiment 2B overview. Participants performed the Box and Block test for 60" with the absence $(0 \mathrm{~kg})$ or presence $(0.5 \mathrm{~kg})$ of an additional weight. Set up consisted of the placement of the heart rate monitor and the EMG surface electrodes. Then, participants completed the indicated questionnaire or scale.

\section{Psychological measurements}

Perception of effort, defined as the conscious sensation of "how hard, heavy and strenuous a physical task is" (Marcora, 2010; Pageaux, 2016), was measured and used to prescribe the exercise with the CR100 scale (Borg \& Kaijser, 2006). This scale ranges from 0 ("nothing at all") to 100 ("maximal") and includes verbal anchors, such as light (weak), moderate, strong (heavy) for intermediate values (Borg \& Kaijser, 2006). Standardized instructions on how to use the CR100 scale to evaluate the perception of effort were provided at the onset of each session and participants were asked to exclude the perception of pain from their rating (Pageaux et al., 2020; Pageaux et al., 2016). To prescribe exercise, participants were asked to perform the tasks at four different effort intensities associated with the following verbal anchors and numbers on the CR100 scale: light (13), moderate (23), strong (50) and very strong (70). To report their perception of effort, participants were asked to first refer to the verbal anchors and then to report a number that best represents the intensity of their perception. The CR100 scale was printed on a legal format $(8.5 \times 14$ in) and fixed on a wall $\sim 1 \mathrm{~m}$ in front of the participants.

Perceived workload was measured with the Nasa Task Load Index (NASA TLX; Hart \& Staveland, 1988). In line with the aims of our study, only the three following subscales were considered: Physical Demand, Temporal Demand and Effort. Participants had to score each of the items on a scale divided into 20 equal intervals anchored by a bipolar descriptor (e.g., High/Low). This score was multiplied by 5 , resulting in a final score between 0 and 100 for each of the six subscales. 
Fatigue. The presence of fatigue is known to increase the perception of effort (Enoka \& Stuart, 1992a; Pageaux \& Lepers, 2016a). We consequently monitored feelings of fatigue at the beginning and the end of each visit with a visual analog scale (Le Mansec et al., 2017). Participants had to place a mark on a $100 \mathrm{~mm}$ line with bipolar end anchors $(0=$ not fatigued at all; $100=$ extremely fatigued $)$. The fatigue score was determined by measuring the distance (in $\mathrm{mm}$ ) from the left-hand end of the line to the mark made by the participant.

\section{Physiological measurements}

298

299

300

301

302

303

304

305

306

307

308

309

310

311

312

313

314

315

316

317

318

319

320

321

Electromyography (EMG) of the biceps brachii and triceps long head was measured in both experiments with adhesive, pre-gelled surface electrodes (Covidien, CA). Before placing the electrodes, the skin was shaved, cleaned with alcohol, and dried. Electrodes were placed using SENIAM recommendations (Hermens et al., 2000). The electrode reference was attached to the extremity of the elbow of the dominant arm. In experiment 1, EMG was recorded using a PowerLab system (26T, ADInstruments) with an acquisition rate of $1 \mathrm{KHz}$ and filtered with bandpass ranging from 20 to $400 \mathrm{~Hz}$ (auto adjust) and a notch filter with a center frequency of $60 \mathrm{~Hz}$ (auto adjust). Data were analyzed using the LabChart software (AD Instruments). In experiment 2, EMG was recorded using a Biopac system (MP150, Biopac Systems, Inc.) with an acquisition rate of $1 \mathrm{KHz}$ and filtered with bandpass ranging from 20 to $400 \mathrm{~Hz}$ (auto adjust) and a notch filter with a center frequency of 60 $\mathrm{Hz}$ (auto adjust). Data were analyzed using Acknowledge software (Biopac Systems, Inc.). The root mean square (RMS) was automatically calculated with each software. Data were averaged for the last $5 \mathrm{~s}$ of each $30 \mathrm{~s}$ (experiment 1) or $60 \mathrm{~s}$ (experiment 2) trials. The EMG is reported as the sum of the triceps and biceps RMS values.

Heart rate frequency was measured in both experiments. In experiment 1, we used a finger pulse transducer (TN1012/ST, AD Instruments) placed on the non-dominant index finger. To limit movement artifacts, the non-dominant hand was placed on homemade support to rest on the table and stay as steady as possible. The signal was recorded with an acquisition rate of $1 \mathrm{KHz}$ and filtered with a digital filter of $7 \mathrm{~Hz}$ (low pass). Data analysis was automatically performed by the LabChart software. Heart rate frequency was averaged for the last $5 \mathrm{~s}$ of each $30 \mathrm{~s}$ trials. Due to numerous movement artifacts in experiment 1, monitoring heart rate was measured using a chest strap via the paired Polar watch (Polar RS400; Polar Electro Oy, Kempele, Finland) and measured as the average of the $60 \mathrm{~s}$ trial. The experimenter pressed the start/stop button of the watch at the beginning and end of each trial, and then recorded the average heart rate frequency calculated by the watch. 
Respiratory frequency was measured in experiment 1 only via a respiratory belt transducer

323 (TN11132/ST, AD Instruments). The respiratory belt was fixed on the participant's chest, the signal was recorded with an acquisition rate of $1 \mathrm{KHz}$ and filtered with a digital filter of $7 \mathrm{~Hz}$ (low pass). Data analysis was automatically performed by the LabChart software. Respiratory frequency was averaged from the last $5 \mathrm{~s}$ of each $30 \mathrm{~s}$ trials.

\section{Statistical Analysis}

All data are presented as mean \pm standard deviation in the text. Assumptions of statistical tests such as normal distribution and sphericity of data were checked as appropriate. Greenhouse-Geisser correction to the degrees of freedom was applied when violation to sphericity was present.

Experiment 1A : All analyses subsequently described were performed for the modified BBT and PT. A $2 \times 4$ repeated-measures ANOVA was used to assess the effects of visit (1 and 2) and effort intensity (light, moderate, strong, very strong) on performance, heart rate frequency, respiratory frequency and EMG RMS. As these analyses were performed to test the possibility to use the perception of effort to prescribe the exercise, a significant main effect of effort intensity only was followed with the following pairwise comparisons adjusted with the Bonferroni correction: light effort vs moderate effort, moderate effort vs strong effort, strong effort vs very strong effort.

Experiment 1B : To test the possibility to monitor changes in perception of effort when task difficulty is altered with manipulation of the physical demand in both tempo and weight sessions, a repeated-measures ANOVA was used to assess the effects of difficulty (easy, medium, hard) on heart rate and respiratory frequencies. Significant effect of difficulty was followed-up with pairwise comparisons adjusted with the Bonferroni correction. A Friedman ANOVA was used to assess the effects of difficulty on performance, rating of perceived effort, EMG RMS, as well as the physical demand, temporal demand and effort subscales of the NASA TLX scale. Significant effect of difficulty was followed up with Wilcoxon signed-ranked tests adjusted with the Bonferroni correction.

Experiment 2A : A repeated-measures ANOVA was used to assess the effects of effort intensity (light, moderate, strong, very strong) on performance, heart rate frequency and EMG RMS. As these analyses were performed to test the possibility to use the perception of effort to prescribe the exercise, a significant effect of effort intensity only was followed with the following pairwise comparisons adjusted with the Bonferroni correction: light effort vs moderate effort, moderate effort vs strong effort, strong effort vs very strong effort. 
A $2 \times 2$ repeated-measures ANOVA was used to assess the effects of repetition (1 and 2) and difficulty (easy and hard) on performance, heart rate frequency, EMG RMS, as well as the physical demand and effort subscales of the NASA TLX scale.

Experiment 2B : As the experiment 2B did not constrain the temporal demand of the task by imposing a tempo, we did not analyze the temporal demand subscale of the NASA TLX scale. If a repetition $\times$ difficulty interaction reached significance, the following follow-up tests were performed and adjusted with the Bonferroni correction: repetition $1 / 0 \mathrm{~kg}$ vs repetition $2 / 0 \mathrm{~kg}$, repetition $1 / 0.5 \mathrm{~kg}$ vs repetition $2 / 0.5 \mathrm{~kg}$, repetition $1 / 0 \mathrm{~kg}$ vs repetition $1 / 0.5 \mathrm{~kg}$, repetition $2 / 0 \mathrm{~kg}$ vs repetition $2 / 0.5 \mathrm{~kg}$.

For both experiments, all statistical analyses were performed using the Statistical Package for the Social Sciences software, version 27 for Mac OS X (SPSS, Chicago, IL). Effect sizes for the repeated measures ANOVA are reported as the partial eta squared $\left(\eta_{\mathrm{p}}{ }^{2}\right)$ provided by SPSS. Effects sizes for the pairwise comparisons are reported with $r$ and calculated with Microsoft Excel according to the equations described below for parametric (i) and non-parametric (Myers et al.) tests (Field, 2005). Parameters $t, d f$ and $Z$ were provided by SPSS, and $N$ corresponds to the total number of observations (Field, 2005).

Significance was set at 0.05 (2-tailed). Thresholds for small, moderate and large effects were set at 0.1, 0.3 and 0.5 for $r$ (Cohen, 1988).

\section{Results}

\section{Experiment 1}

In this experiment, we used a modified version of the BBT and PT. We prescribed $30 \mathrm{~s}$ of exercise performed at four intensities of effort (light, moderate, strong and very strong) in two different visits. Performance, EMG RMS, heart rate and respiratory frequencies were monitored for each prescribed effort intensity. We also manipulated task difficulty levels (low, moderate, high) by manipulating physical demand and imposing three tempos or adding three different weights on the participant's dominant forearm while performing the task at a fixed tempo. Performance, heart rate frequency, respiratory frequency, EMG RMS and the subjective workload were measured for each difficulty. 


\section{a. Experiment 1A: Using the perception of effort to prescribe the exercise}

382 Results of the main effects of effort intensity for the BBT and PT are presented in figures 3 and 4 , respectively.

Performance: For the BBT (figure 3A), the main effect of visit did not reach significance $[F(1,19)$

$\left.=2.105, p=.163, \eta_{p}^{2}=.099\right]$. Increasing the prescribed effort intensity resulted in an increased performance during the $\operatorname{BBT}\left[F(1.6,31.2)=172.335, p<.001, \eta_{p}{ }^{2}=.901\right]$. Follow-up test revealed an increase in performance between the light and moderate intensities $[\mathrm{t}(19)=10.509, \mathrm{p}<.001, \mathrm{r}=$ $.924]$, between the moderate and strong intensities $[\mathrm{t}(19)=10.474, \mathrm{p}<.001, \mathrm{r}=.923]$, as well as between the strong and very strong intensities $[\mathrm{t}(19)=7.191, \mathrm{p}<.001, \mathrm{r}=.855]$. The visit $\times$ effort intensity interaction did not reach significance $\left[F(3,57)=.401, \mathrm{p}=.752, \eta_{\mathrm{p}}{ }^{2}=.021\right]$. For the PT (figure $4 \mathrm{~A})$, the main effect of visit did not reach significance $\left[F(1,19)=.749, \mathrm{p}=.397, \eta_{\mathrm{p}}{ }^{2}=.038\right]$. The main effect of effort intensity reached significance $\left[F(1.6,31.1)=112.050, p<.001, \eta_{p}^{2}=.855\right]$. Followup test revealed an increase in performance between the light and moderate intensities $[\mathrm{t}(19)=8.162$, $\mathrm{p}<.001, \mathrm{r}=.882]$, between the moderate and strong intensities $[\mathrm{t}(19)=10.681, \mathrm{p}<.001, \mathrm{r}=.926]$, as well as between the strong and very strong intensities $[\mathrm{t}(19)=6.291, \mathrm{p}<.001, \mathrm{r}=.822]$. The visit $\times$ effort intensity interaction did not reach significance $\left[F(1.4,26.8)=1.342, \mathrm{p}=.270, \eta_{\mathrm{p}}{ }^{2}=.065\right]$.

EMG RMS: For the BBT (figure 3B), the main effect of visit did not reach significance $[F(1,18)=$ $\left.2.377, \mathrm{p}=.140, \eta_{\mathrm{p}}{ }^{2}=.116\right]$. The main effect of effort intensity reached significance $[F(1.4,24.7)=$ 37.667, $\left.\mathrm{p}<.001, \eta_{\mathrm{p}}{ }^{2}=.676\right]$. Follow-up test revealed an increase in EMG RMS between light and moderate intensities $[\mathrm{t}(18)=5.904, \mathrm{p}<.001, \mathrm{r}=.812]$, between the moderate and strong intensities $[\mathrm{t}(18)=5.229, \mathrm{p}<.001, \mathrm{r}=.777]$, as well as between the strong and very strong intensities $[\mathrm{t}(18)=$ $4.110, \mathrm{p}=.002, \mathrm{r}=.696]$. The visit $\times$ effort intensity interaction did not reach significance $[F(3,54)=$ $\left..668, \mathrm{p}=.575, \eta_{\mathrm{p}}{ }^{2}=.036\right]$. For the PT (figure 4B), the main effect of visit did not reach significance $\left[F(1,18)=.247, \mathrm{p}=.625, \eta_{\mathrm{p}}^{2}=.013\right]$. The main effect of effort reached significance $[F(1.2,22.7)=$ 44.335, $\left.p<.001, \eta_{p}{ }^{2}=.711\right]$. Follow-up test revealed an increase in EMG RMS between light and moderate intensities $[\mathrm{t}(18)=6.049, \mathrm{p}<.001, \mathrm{r}=.819]$, between the moderate and strong intensities

$$
\left.=.873, \mathrm{p}=.412, \eta_{\mathrm{p}}^{2}=.046\right] \text {. }
$$


412 Heart rate frequency: For the BBT (figure 3C), the main effect of visit did not reach significance $413\left[F(1,8)=.851, \mathrm{p}=.383, \eta_{\mathrm{p}}{ }^{2}=.096\right]$. The main effect of effort intensity reached significance $[F(3,24)$ $\left.414=8.166, \mathrm{p}=.001, \eta_{\mathrm{p}}^{2}=.505\right]$. Follow-up test revealed an increase in heart rate frequency between the 415 moderate and strong intensities $[\mathrm{t}(17)=3.176, \mathrm{p}=.017, \mathrm{r}=.610]$. Neither the increase in heart rate 416 frequency between the light and moderate intensities $[\mathrm{t}(17)=1.490, \mathrm{p}=.464, \mathrm{r}=.340]$, nor the one 417 between the strong and very strong intensities did reach significance $[\mathrm{t}(17)=0.334, \mathrm{p}=1.000, \mathrm{r}=$ $418.081]$. The visit $\times$ effort intensity interaction did not reach significance $\left[F(3,24)=.896, \mathrm{p}=.458, \eta_{\mathrm{p}}^{2}=\right.$ $419.101]$. For the PT (figure 4C), the main effect of visit did not reach significance $[F(1,14)=.218, \mathrm{p}=$ $\left.420.647, \eta_{\mathrm{p}}^{2}=.015\right]$. The main effect of effort reached significance $\left[F(3,42)=14.804, \mathrm{p}<.001, \eta_{\mathrm{p}}{ }^{2}=\right.$ $421.513]$. Follow-up test revealed an increase in heart rate frequency between the moderate and strong 422 intensities $[\mathrm{t}(19)=3.285, \mathrm{p}=.012, \mathrm{r}=.602]$, but not between the light and moderate intensities [ $\mathrm{t}(19)$ $423=2.182, \mathrm{p}=.126, \mathrm{r}=.448]$ not between the strong and very strong intensities $[\mathrm{t}(19)=1.941, \mathrm{p}=.202$, $424 \mathrm{r}=.407]$. The visit $\times$ effort intensity interaction did not reach significance $[F(3,42)=.406, \mathrm{p}=.748$, $\left.425 \quad \eta_{\mathrm{p}}^{2}=.028\right]$.

Respiratory frequency: For the BBT (figure 3D), the main effect of visit did not reach significance 428 $\left[F(1,13)=.008, \mathrm{p}=.930, \eta_{\mathrm{p}}^{2}=.001\right]$. The main effect of effort intensity reached significance $[F(3,39)$ $\left.=6.463, \mathrm{p}=.001, \eta_{\mathrm{p}}^{2}=.332\right]$. However, neither the increase in respiratory frequency between the light and moderate intensities $[\mathrm{t}(19)=2.450, \mathrm{p}=.072, \mathrm{r}=.490]$, nor between the moderate and strong intensities $[\mathrm{t}(19)=2.131, \mathrm{p}=.139, \mathrm{r}=.439]$ or between the strong and very strong intensities did reach significance $[\mathrm{t}(19)=1.663, \mathrm{p}=.338, \mathrm{r}=.357]$. The visit $\times$ effort intensity interaction did not reach significance $\left[F(3,39)=.084, \mathrm{p}=.970, \eta_{\mathrm{p}}{ }^{2}=.006\right]$. For the PT (figure 4D), the main effect of visit did not reach significance $\left[F(1,15)=.142, \mathrm{p}=.711, \eta_{\mathrm{p}}^{2}=.009\right]$. The main effect of effort intensity reached significance $\left[F(3,45)=10.893, \mathrm{p}<.001, \eta_{\mathrm{p}}{ }^{2}=.421\right]$. However, again, neither the increase in respiratory frequency between the light and moderate intensities $[\mathrm{t}(19)=1.648, \mathrm{p}=.347, \mathrm{r}=.354]$, nor between the moderate and strong intensities $[\mathrm{t}(19)=2.451, \mathrm{p}=.072, \mathrm{r}=.490]$ or between the strong and very interaction did not reach significance $\left[F(3,45)=.195, \mathrm{p}=.899, \eta_{\mathrm{p}}{ }^{2}=.012\right]$. 
A
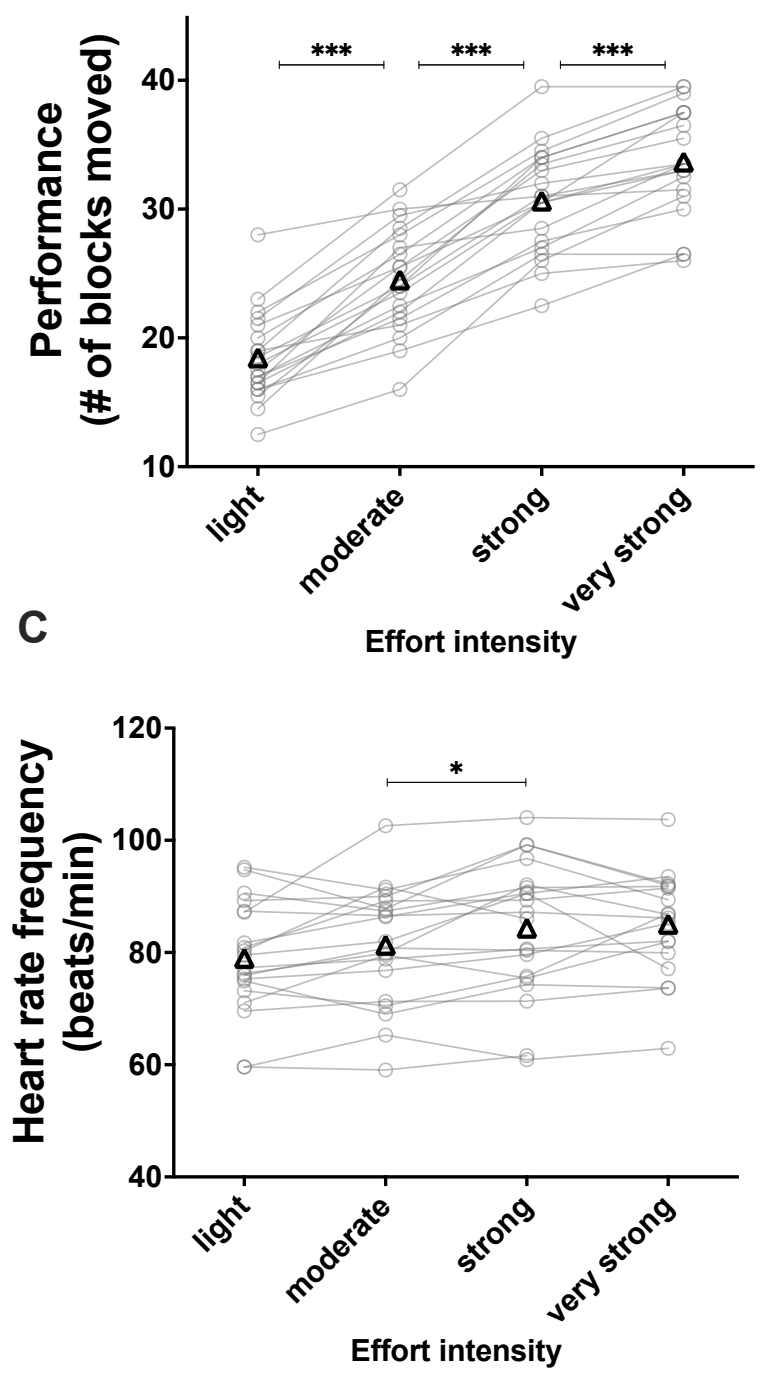

B
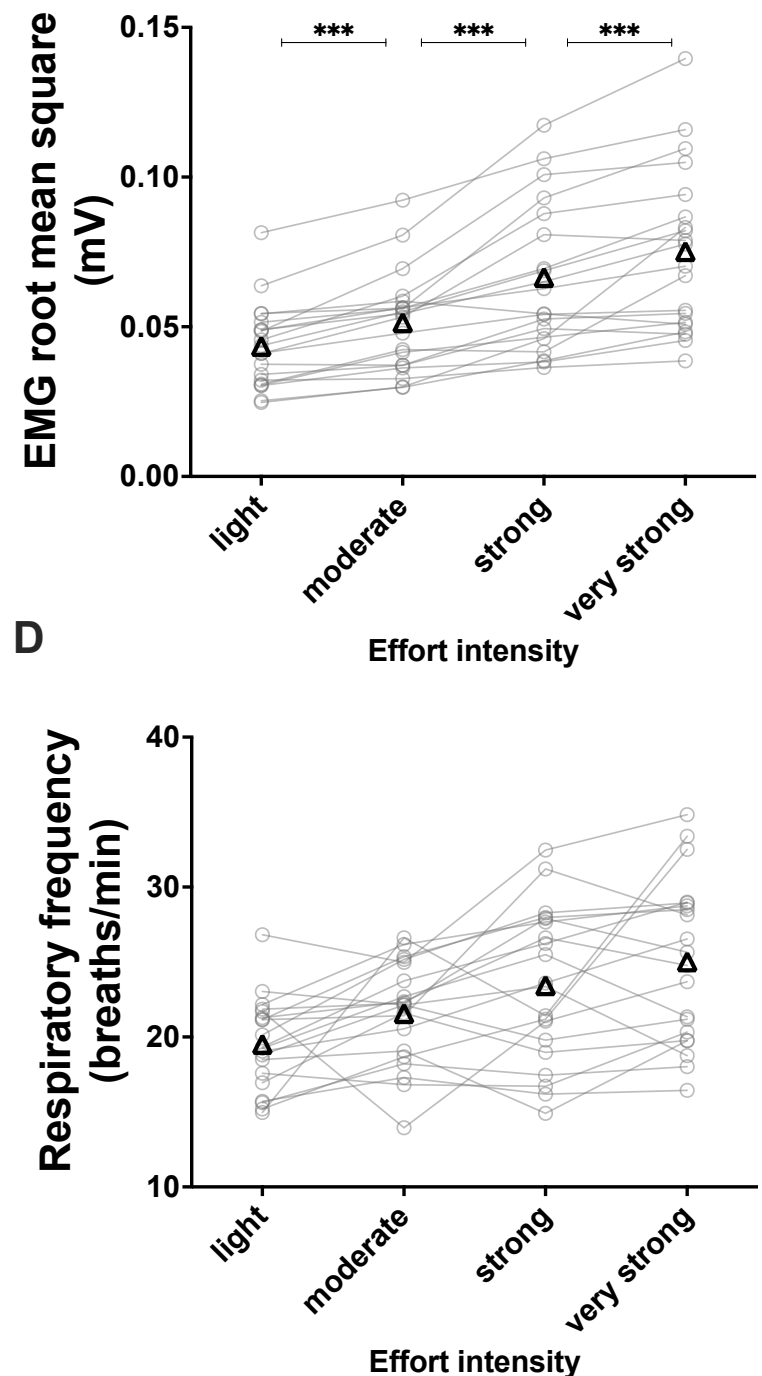

\section{Figure 3. Experiment 1A: using the perception of effort to prescribe the exercise during the}

\section{Box and Block test.}

Effect of increasing the prescribed effort intensity on performance (panel A, $n=20$ ), EMG root mean square of the sum of the biceps and triceps brachial muscles (panel $B, n=19$ ), heart rate frequency (panel $\mathrm{C}, \mathrm{n}=18$ ) and respiratory frequency (panel $\mathrm{D}, \mathrm{n}=20$ ) during the Box and Block Test. The exercise was prescribed at four intensities of perceived effort via the CR100 scale: light (13/100), moderate (23/100), strong (50/100), very strong (70/100). Data are presented as the main effect of effort intensity. The $\mathrm{n}$ indicates the number of participants with all the data in each four effort intensities. Changes in the $\mathrm{n}$ reflects data loss due to the issue with equipment or movement artefact. Individual data are presented in grey circles and means in black triangles. ${ }^{*}$ difference between two intensities of effort. One symbol for $\mathrm{p}<0.05$, two symbols for $\mathrm{p}<0.01$ and three symbols for $\mathrm{p}<$ 0.001 . 
A

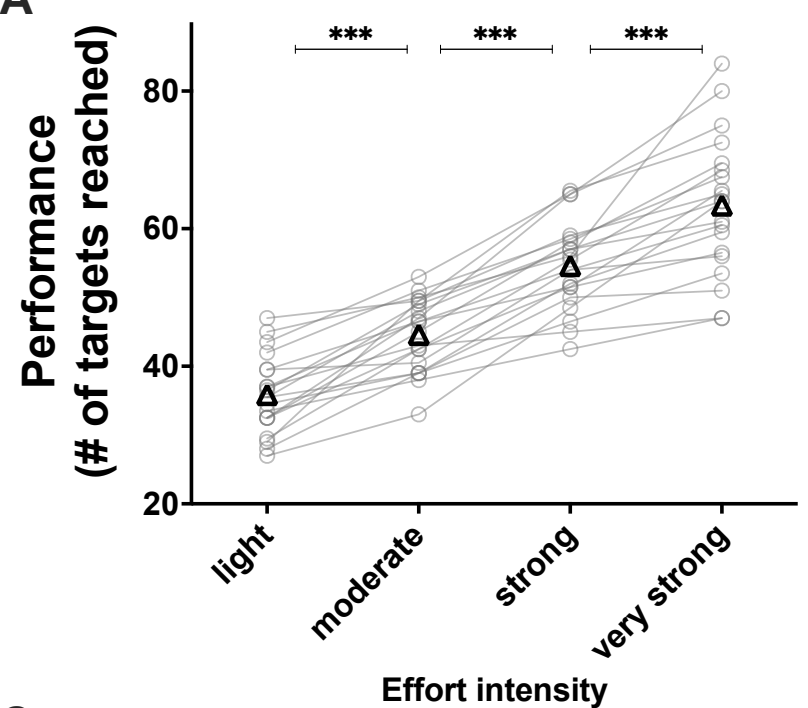

C

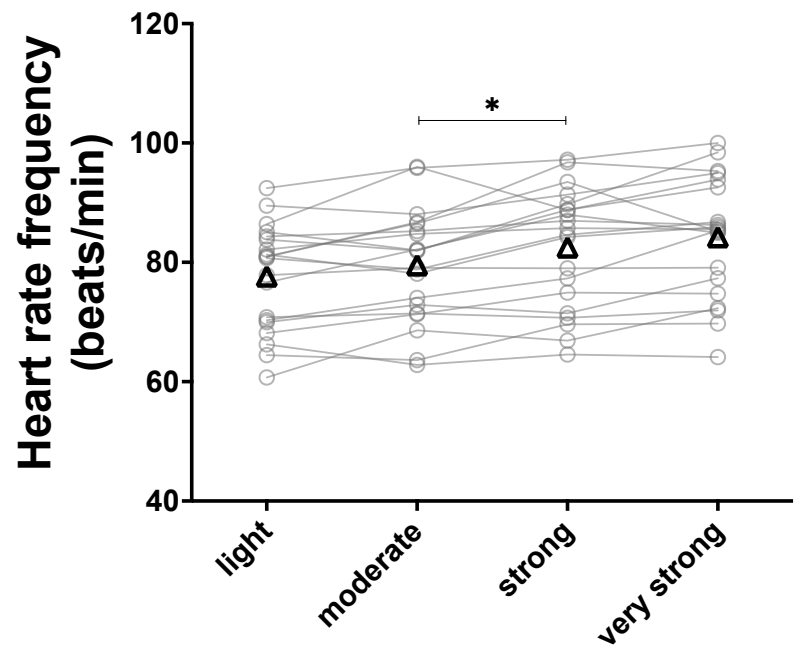

Effort intensity

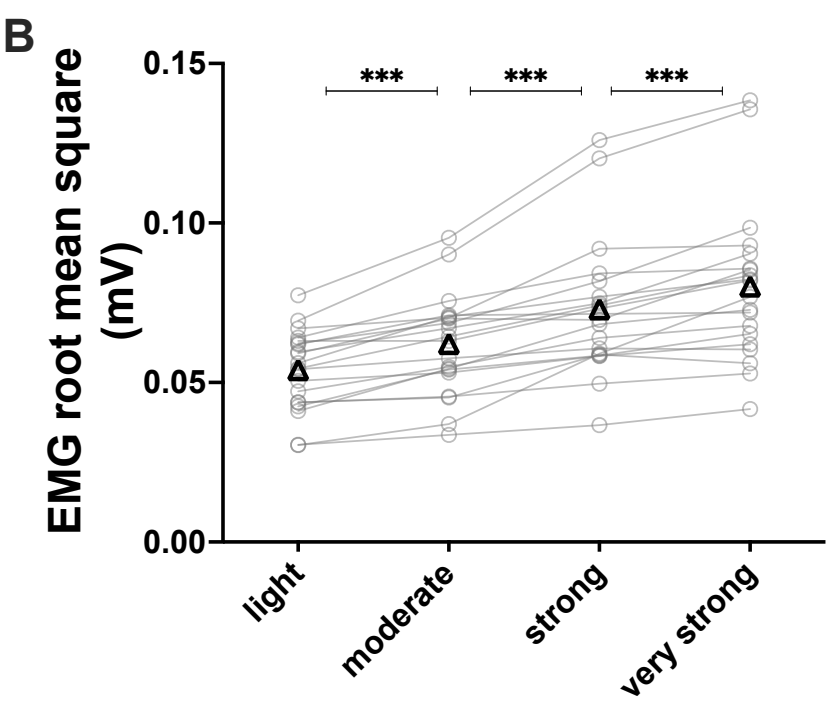

Effort intensity

D

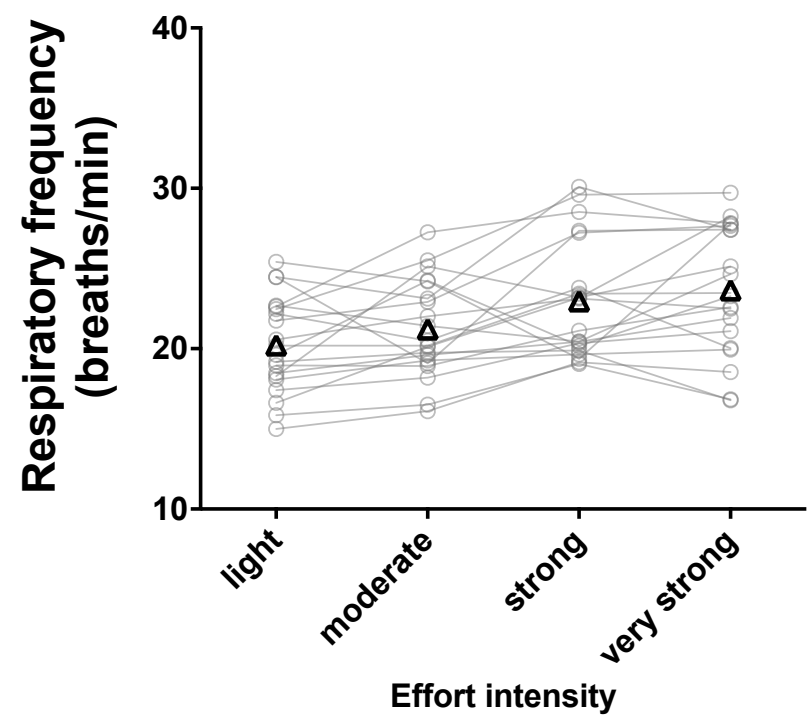

Figure 4. Experiment 1A: using the perception of effort to prescribe the exercise during the Pointing task.

Effect of increasing the prescribed effort intensity on performance (panel A, $n=20$ ), EMG root mean square of the sum of the biceps and triceps brachial muscles (panel $B, n=20$ ), heart rate frequency (panel $\mathrm{C}, \mathrm{n}=20$ ) and respiratory frequency (panel $\mathrm{D}, \mathrm{n}=20$ ) during the Pointing Task. The exercise was prescribed at four intensities of perceived effort via the CR100 scale: light (13/100), moderate (23/100), strong (50/100), very strong (70/100). Data are presented as the main effect of effort intensity. Individual data are presented in grey circles and means in black triangles. $*$ difference between two 
463

464

465

466

467

468

469

470

471

472

473

474

475

476

477

478

479

480

481

482

483

484

485

486

487

488

489

490

491

492

intensities of effort. One symbol for $\mathrm{p}<0.05$, two symbols for $\mathrm{p}<0.01$ and three symbols for $\mathrm{p}<$ 0.001 .

\section{b. Experiment 1B : Manipulating the tempo to alter task difficulty.}

Results for the BBT and PT during the tempo sessions are presented in figures 5 and 6, respectively.

Performance: For the BBT (figure 5A), manipulation of the tempo increased performance $\left[\chi^{2}(2)=\right.$ $40, \mathrm{p}<.001]$. Performance increased between the low and moderate difficulties $(Z=3.990, \mathrm{p}<.001$, $r=.631)$, between the low and high difficulties $(Z=3.935, p<.001, r=.622)$, as well as between the moderate and high difficulties $(Z=3.941, \mathrm{p}<.001, \mathrm{r}=.623)$. One participant did not show an increase in performance between the moderate and high difficulties, as shown in the figure. For the PT (figure $6 \mathrm{~A})$, manipulation of the tempo increased performance too $\left[\chi^{2}(2)=40, p<.001\right]$. Performance increased between the low and moderate difficulties $(\mathrm{Z}=3.965, \mathrm{p}<.001, \mathrm{r}=.627)$, between the low and high difficulties $(\mathrm{Z}=3.941, \mathrm{p}<.001, \mathrm{r}=.623)$, as well as between the moderate and high difficulties $(\mathrm{Z}=3.932, \mathrm{p}<.001, \mathrm{r}=.622)$.

Perception of effort: For the BBT (figure 5B), manipulation of the tempo increased the rating of perceived effort $\left[\chi^{2}(2) .=30.152, \mathrm{p}<.001\right]$. Rating of perceived effort increased between the low and moderate difficulties $(Z=3.747, p=.001, r=.592)$, between the low and high difficulties $(Z=3.790$, $\mathrm{p}<.001, \mathrm{r}=.599)$, as well as between the moderate and high difficulties $(\mathrm{Z}=3.460, \mathrm{p}=.002, \mathrm{r}=.547)$. For the PT (figure 6B), manipulation of the tempo increased the rating of perceived effort too $\left[\chi^{2}(2)\right.$. $=36.1, \mathrm{p}<.001]$. Rating of perceived effort increased between the low and moderate difficulties $(\mathrm{Z}=$ $3.865, \mathrm{p}<.001, \mathrm{r}=.611)$, between the low and high difficulties $(\mathrm{Z}=3.921, \mathrm{p}<.001, \mathrm{r}=.620)$, as well as between the moderate and high difficulties $(\mathrm{Z}=3.883, \mathrm{p}<.001, \mathrm{r}=.614)$.

$E M G R M S$ : For the BBT (figure 5C), manipulation of the tempo increased the EMG RMS $\left[\chi^{2}(2)\right.$. $=27.9, \mathrm{p}<.001]$. EMG RMS increased between the low and moderate difficulties $(\mathrm{Z}=3.285, \mathrm{p}=.003$, $\mathrm{r}=.519)$, between the low and high difficulties $(\mathrm{Z}=3.360, \mathrm{p}=.002, \mathrm{r}=.531)$, as well as between the moderate and high difficulties $(Z=3.024, p=.007, r=.478)$. For the PT (figure $6 \mathrm{C}$ ), manipulation of the tempo increased the EMG RMS too $\left[\chi^{2}(2) .=40, \mathrm{p}<.001\right]$. EMG RMS increased between the low and moderate difficulties $(Z=3.920, \mathrm{p}<.001, \mathrm{r}=.620)$, between the low and high difficulties $(Z=3$. $920, \mathrm{p}<.001, \mathrm{r}=.620)$, as well as between the moderate and high difficulties $(Z=3.920, \mathrm{p}<.001, \mathrm{r}$ $=.620)$. 
493

494

495

496

497

498

499

500

501

502

503

504

505

506

507

508

509

510

511

512

513

514

515

516

517

518

519

520

521

522

523

524

Heart rate frequency: Despite controlling for movement artifacts data was lost in two participants during the BBT and two participants during the PT, both during the completion of the high difficulty. For the BBT (figure 5D), manipulation of the tempo increased the heart rate frequency $[F(2,34)=$ 9.826, $\left.p<.001, \eta_{\mathrm{p}}^{2}=.366\right]$. Heart rate frequency increased between the low and moderate difficulties $[\mathrm{t}(19)=2.517, \mathrm{p}<.001, \mathrm{r}=.500]$, between the low and high difficulties $[\mathrm{t}(17)=3.861, \mathrm{p}<.001, \mathrm{r}=$ .684], as well as between the moderate and high difficulties $[\mathrm{t}(17)=2.297, \mathrm{p}<.001, \mathrm{r}=.487]$. For the PT (figure 6D), manipulation of the tempo increased the heart rate frequency too $[F(2,34)=15.707, p$ $\left.<.001, \eta_{\mathrm{p}}{ }^{2}=.480\right]$. Heart rate frequency increased between the low and moderate difficulties $[\mathrm{t}(19)=$ 2.707, $\mathrm{p}=.042, \mathrm{r}=.528]$, between the low and high difficulties $[\mathrm{t}(17)=4.911, \mathrm{p}<.001, \mathrm{r}=.766]$, as well as between the moderate and high difficulties $[\mathrm{t}(17)=3.604, \mathrm{p}=.007, \mathrm{r}=.658]$.

Respiratory frequency: For the BBT (figure 5E), manipulation of the tempo increased the respiratory frequency $\left[F(2,38)=10.5, p<.001, \eta_{\mathrm{p}}^{2}=.355\right]$. The increase in respiratory frequency between the low and moderate difficulties did not reach significance $[\mathrm{t}(19)=2.373, \mathrm{p}=.085, \mathrm{r}=.478]$. Respiratory frequency increased between the low and high difficulties $[\mathrm{t}(19)=3.797, \mathrm{p}=.004, \mathrm{r}=.657]$ as well as between the moderate and high difficulties $[\mathrm{t}(19)=2.8, \mathrm{p}=.036, \mathrm{r}=.537]$. For the PT (figure $6 \mathrm{E})$, manipulation of the tempo increased the respiratory frequency too $\left[F(2,38)=5.3, p=.009, \eta_{\mathrm{p}}^{2}\right.$ $=.219]$. Respiratory frequency increased between the moderate and high difficulties $[\mathrm{t}(19)=3.380, \mathrm{p}$ $=.009, \mathrm{r}=.613]$. The increase in respiratory frequency neither reached significance between the low and high difficulties $[\mathrm{t}(19)=2.391, \mathrm{p}=.082, \mathrm{r}=.481]$, nor between the low and moderate difficulties $[\mathrm{t}(19)=.184, \mathrm{p}=1.000, \mathrm{r}=.042]$.

NASA TLX scale, physical demand: For the BBT (figure 5F), manipulation of the tempo increased the physical demand score $\left[\chi^{2}(2) .=17.815, \mathrm{p}<.001\right]$. The increase in physical demand score between the easy and medium difficulties did not reach significance $(Z=2.213, \mathrm{p}=.081, \mathrm{r}=.350)$. Physical demand score increased between the low and high difficulties $(Z=3.307, \mathrm{p}=.003, \mathrm{r}=.523)$ as well as between the moderate and high difficulties $(\mathrm{Z}=3.051, \mathrm{p}=.007, \mathrm{r}=.482)$. For the PT (figure $6 \mathrm{~F}$ ), manipulation of the tempo increased the physical demand score too $\left[\chi^{2}(2) .=14.464, p=.001\right]$. Physical demand score did not increase between the low and moderate difficulties $(Z=1.690, p=.273, r=$ .267). Physical demand score increased between the low and high difficulties $(Z=3.354, p=.002, r=$ $.530)$ as well as between the moderate and high difficulties $(Z=3.066, \mathrm{p}=.007, \mathrm{r}=.485)$.

NASA TLX scale, temporal demand: For the BBT (figure 5G), manipulation of the tempo increased the temporal demand score $\left[\chi^{2}(2) .=7.28, \mathrm{p}=.026\right]$. Temporal demand score neither increased between the low and moderate difficulties $(Z=.572, \mathrm{p}=1.000, \mathrm{r}=.090)$, nor between the low and high 
525 difficulties $(Z=2.194, \mathrm{p}=.085, \mathrm{r}=.347)$. Temporal demand score significantly increased between the 526 moderate and high difficulties $(\mathrm{Z}=2.686, \mathrm{p}=.022, \mathrm{r}=.425)$. For the PT (figure $6 \mathrm{G})$, manipulation of

527 the tempo increased the temporal demand score too $\left[\chi^{2}(2) .=23.792, p<.001\right]$. The increase in 528 temporal demand score between the low and moderate difficulties did not reach significance $(Z=$ $5292.144, \mathrm{p}=.096, \mathrm{r}=.339)$. Temporal demand score significantly increased between the low and high 530 difficulties $(\mathrm{Z}=3.712, \mathrm{p}=.001, \mathrm{r}=.587)$ as well as between the moderate and high difficulties $(\mathrm{Z}=$ $5313.736, \mathrm{p}=.001, \mathrm{r}=.591)$.

532 NASA TLX scale, effort: For the BBT (figure 5H), manipulation of the tempo increased the effort 533 score $\left[\chi^{2}(2) .=18.123, \mathrm{p}<.001\right]$. Effort score did not increase between the low and moderate 534 difficulties $(\mathrm{Z}=.177, \mathrm{p}=1.000, \mathrm{r}=.028)$ but did so between the low and high difficulties $(\mathrm{Z}=3.184$, $535 \mathrm{p}=.004, \mathrm{r}=.503)$, as well as between the moderate and high difficulties $(\mathrm{Z}=3.202, \mathrm{p}=.004, \mathrm{r}=.506)$.

536 For the PT (figure $6 \mathrm{H}$ ), manipulation of the tempo increased the effort demand score too $\left[\chi^{2}(2)\right.$. $=$ $53722.776, \mathrm{p}<.001]$. Effort score did not increase between the low and moderate difficulties $(Z=1.759$, $538 \mathrm{p}=.236, \mathrm{r}=.278)$ but did so between the low and high difficulties $(\mathrm{Z}=3.637, \mathrm{p}=.001, \mathrm{r}=.575)$, as 539 well as between the moderate and high difficulties $(\mathrm{Z}=2.882, \mathrm{p}=.012, \mathrm{r}=.456)$.

540 VAS fatigue: Feelings of fatigue did not increase during the tempo session (from $2.9 \pm 2.2$ to $3.2 \pm$ $5411.9 ; \mathrm{Z}=.952, \mathrm{p}=.340)$.

542

A

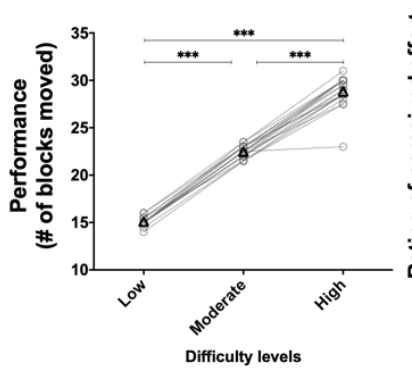

E

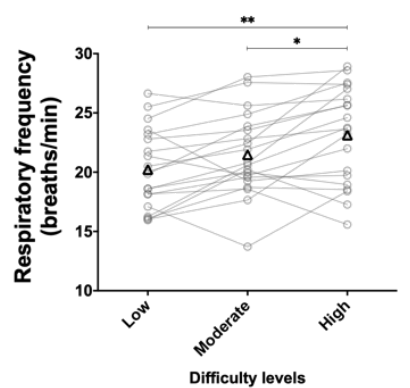

B

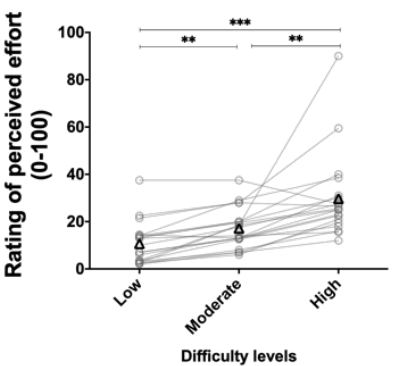

$\mathbf{F}$

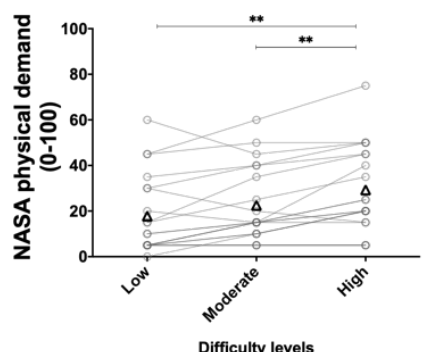

C

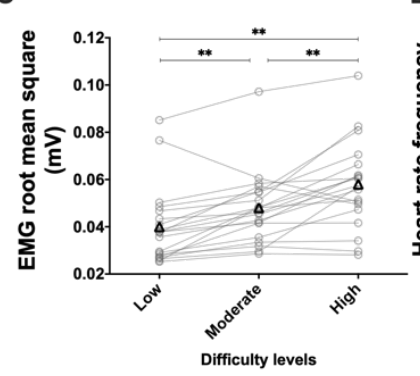

G

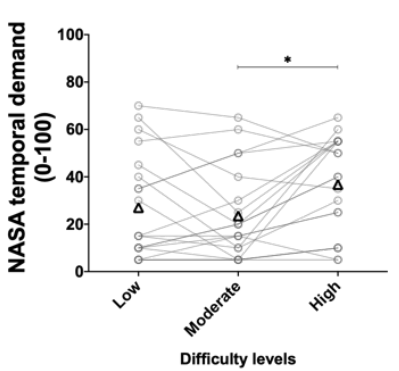

D

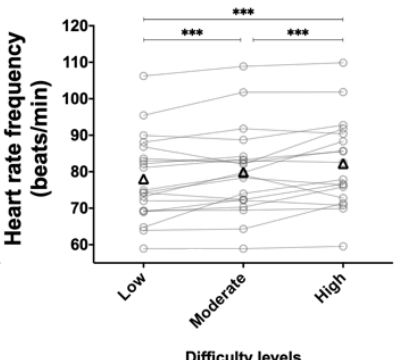

H

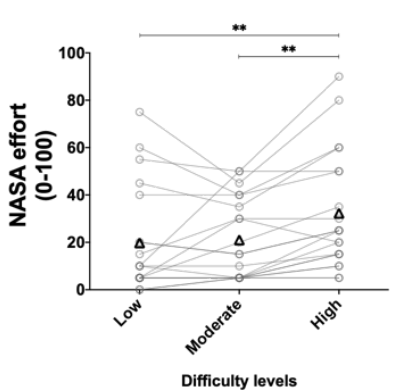




\section{Figure 5. Experiment 1B: Manipulating the tempo to alter task difficulty during the Box and} block test.

546 Effect of manipulating the tempo during the Box and Block Test on performance (panel A, $\mathrm{n}=20$ ), Rating of perceived effort (panel $B, n=20$ ), EMG root mean square of the sum of the biceps and triceps brachial muscles (panel $\mathrm{C}, \mathrm{n}=20$ ), heart rate frequency (panel $\mathrm{D}, \mathrm{n}=18$ ), respiratory frequency (panel $\mathrm{E}, \mathrm{n}=20$ ) and NASA TLX scores for physical demand (panel $\mathrm{F}, \mathrm{n}=20$ ), temporal demand (panel $\mathrm{G}$, $\mathrm{n}=20$ ) and subjective effort (panel $\mathrm{H}, \mathrm{n}=20$ ). For the low difficulty, a $0.5 \mathrm{~Hz}$ tempo was imposed. For the moderate difficulty, a $0.75 \mathrm{~Hz}$ tempo was imposed. For the high difficulty, a $1 \mathrm{~Hz}$ tempo was imposed. Data are presented as the main effect of difficulty. The $\mathrm{n}$ indicates the number of participants with all the data in each three level of difficulties. Changes in the $\mathrm{n}$ reflects data loss due to the issue with equipment or movement artefact. Individual data are presented in grey circles and means in black triangles. * difference between two difficulty level. One symbol for $\mathrm{p}<0.05$, two symbols for $\mathrm{p}<0.01$ and three symbols for $\mathrm{p}<0.001$.

558
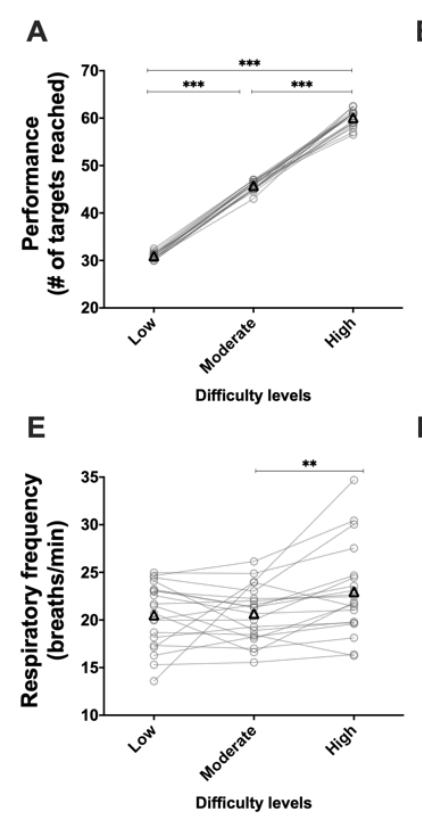

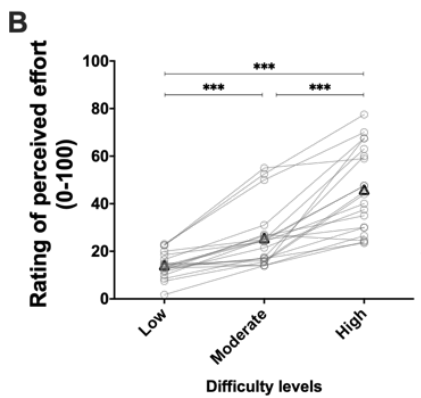

$\mathbf{F}$

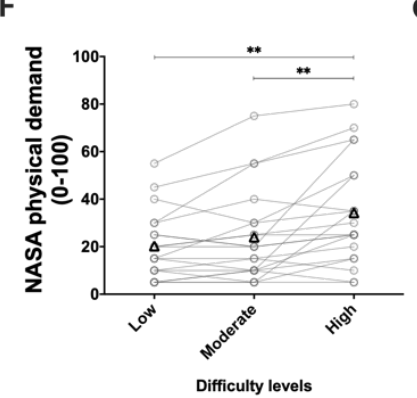

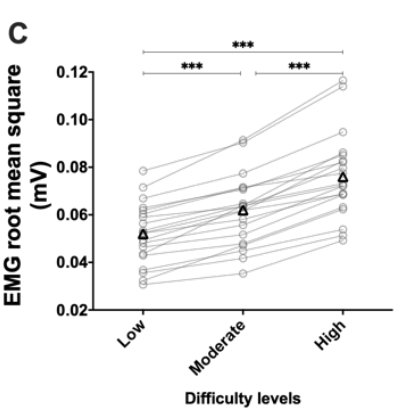

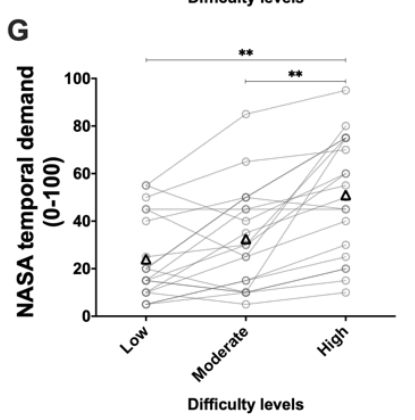

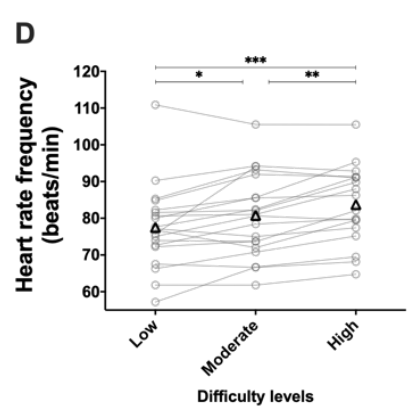

H

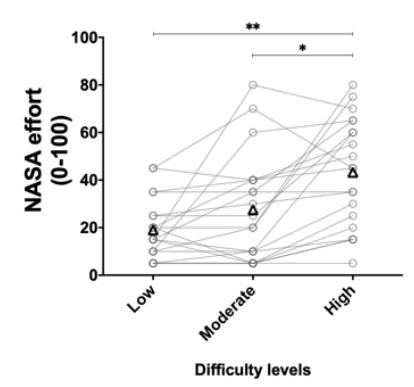

Figure 6. Experiment 1B: Manipulating the tempo to alter task difficulty during the Pointing task.

Effect of manipulating the tempo during the Pointing Task on performance (panel A, $n=20$ ), Rating of perceived effort (panel $\mathrm{B}, \mathrm{n}=20$ ), EMG root mean square of the sum of the biceps and triceps brachial muscles (panel $\mathrm{C}, \mathrm{n}=20$ ), heart rate frequency (panel $\mathrm{D}, \mathrm{n}=18$ ), respiratory frequency (panel $\mathrm{E}, \mathrm{n}=20$ ) and NASA TLX scores for physical demand (panel $\mathrm{F}, \mathrm{n}=20$ ), temporal demand (panel $\mathrm{G}$, $\mathrm{n}=20$ ) and subjective effort (panel $\mathrm{H}, \mathrm{n}=20$ ). For the low difficulty, a $1 \mathrm{~Hz}$ tempo was imposed. For the moderate difficulty, a $1.5 \mathrm{~Hz}$ tempo was imposed. For the high difficulty, a $2 \mathrm{~Hz}$ tempo was imposed. Data are presented as the main effect of difficulty. The $\mathrm{n}$ indicates the number of participants 
with equipment or movement artefact. Individual data are presented in grey circles and means in black triangles. $*$ difference between two difficulty level. One symbol for $p<0.05$, two symbols for $p<0.01$ and three symbols for $\mathrm{p}<0.001$.

\section{c. Experiment 1B : Adding weight on the forearm to alter task difficulty}

Results for the BBT and PT during the weight sessions are presented in figures 7 and 8 , respectively.

Performance: For the BBT (figure 7A) and PT (figure 8A), manipulation of the weight did not alter performance $\left[\mathrm{BBT},\left(\chi^{2}(2)=4.899, \mathrm{p}=.086 ; \mathrm{PT} \chi^{2}(2)=2.032, \mathrm{p}=.362\right]\right.$.

Perception of effort: For the BBT (figure 7B), manipulation of the weight increased the rating of perceived effort $\left[\chi^{2}(2) .=36.026, p<.001\right]$. Rating of perceived effort increased between the low and moderate difficulties $(Z=3.341, \mathrm{p}=.003, \mathrm{r}=.528)$, between the low and high difficulties $(\mathrm{Z}=3.921$, $\mathrm{p}<.001, \mathrm{r}=.620)$, as well as between the moderate and high difficulties $(\mathrm{Z}=3.624 \mathrm{p}=.001, \mathrm{r}=.573)$. For the PT (figure 8B), manipulation of the weight increased the rating of perceived effort too $\left[\chi^{2}(2)\right.$. $=32.076, \mathrm{p}<.001]$. Rating of perceived effort increased between the low and moderate difficulties $(Z$ $=3.324, p=.003, r=.526)$, between the low and high difficulties $(Z=3.920, p<.001, r=.620)$, as well as between the moderate and high difficulties $(\mathrm{Z}=3.502, \mathrm{p}=.001, \mathrm{r}=.554)$.

Heart rate frequency: Despite controlling for movement artifacts data was lost during the BBT in four participants during the completion of the moderate difficulty and in one participant during the completion of the high difficulty. During the PT, data was lost in two participants during the completion of the low difficulty, in one participant during the completion of the moderate difficulty and in one participant during the completion of the high difficulty. For the BBT (figure 7C), manipulation of the weight increased the heart rate frequency $\left[F(2,30)=13.758, p<.001, \eta_{\mathrm{p}}{ }^{2}=.478\right]$. Heart rate frequency did not increase between the low and moderate difficulties $[t(15)=.748, \mathrm{p}=1.000, \mathrm{r}=.190]$ but did so between the low and high difficulties $[\mathrm{t}(15)=4.213, \mathrm{p}=.002, \mathrm{r}=.736]$, as well as between the moderate and high difficulties $[\mathrm{t}(15)=5.115, \mathrm{p}<.001, \mathrm{r}=.797]$. For the PT (figure 8C), manipulation of the weight significantly increased the heart rate frequency too $\left[F(2,32)=11.257, p<.001, \eta_{\mathrm{p}}{ }^{2}\right.$ $=.413]$ The increase in heart rate frequency between the low and moderate difficulties $[\mathrm{t}(16)=2.636$, $\mathrm{p}=.054, \mathrm{r}=.550]$ as well as between the moderate and high difficulties $[\mathrm{t}(16)=2.541, \mathrm{p}=.065, \mathrm{r}=$ .536] did not reach significance. Heart rate frequency significantly increased between the low and high difficulties $[\mathrm{t}(16)=4.190, \mathrm{p}=.002, \mathrm{r}=.723]$. 
$E M G R M S$ : For the BBT (figure 7D), manipulation of the weight increased the EMG RMS $\left[\chi^{2}(2)\right.$.

600

601

602

603

604

605

606

607

608

609

610

611

612

613

614

615

616

617

618

619

620

621

622

623

624

625

626

627

628

$=31.3, \mathrm{p}<.001]$. EMG RMS increased between the low and moderate difficulties $(Z=2.987, \mathrm{p}=.008$, $\mathrm{r}=.472)$, between the low and high difficulties $(\mathrm{Z}=3.323, \mathrm{p}=.003, \mathrm{r}=.525)$, as well as between the moderate and high difficulties $(\mathrm{Z}=3.920, \mathrm{p}<.001, \mathrm{r}=.620)$. For the PT (figure $8 \mathrm{D})$, manipulation of the weight increased the EMG RMS too $\left[\chi^{2}(2) .=14.8, p=.001\right]$. EMG RMS did not increase between the low and moderate difficulties $(\mathrm{Z}=.000, \mathrm{p}=1.000, \mathrm{r}=0)$ but did so between the low and high difficulties $(\mathrm{Z}=2.061, \mathrm{p}=.007, \mathrm{r}=.326)$, as well as between the moderate and high difficulties $(\mathrm{Z}=$ $3.285, \mathrm{p}=.003, \mathrm{r}=.519)$.

Respiratory frequency: During the BBT, data was lost in one participant during the completion of both the low and high difficulties. During the PT, data was lost in one participant for the three difficulties and in one participant during the high difficulty. For the BBT (figure 7E) and PT (figure $8 \mathrm{E}$ ), manipulation of the weight did not alter respiratory frequency [BBT, $F(2,36)=1.931, p=.159$, $\eta_{\mathrm{p}}^{2}=.097$; PT, $\left.F(2,34)=1.477, p=.243, \eta_{\mathrm{p}}^{2}=.080\right]$.

NASA TLX scale, physical demand: For the BBT (figure 7F), manipulation of the weight increased the physical demand score $\left[\chi^{2}(2) .=18.2, p<.001\right]$. Physical demand score increased between the low and moderate difficulties $(\mathrm{Z}=3.373, \mathrm{p}=.002, \mathrm{r}=.533)$, between the moderate and high difficulties $(\mathrm{Z}$ $=2.630, \mathrm{p}=.026, \mathrm{r}=.416)$, as well as between the low and high difficulties $(\mathrm{Z}=3.497, \mathrm{p}=.001, \mathrm{r}=$ .553 ). For the PT (figure $8 \mathrm{~F}$ ), manipulation of the weight significantly increased the physical demand score too $\left[\chi^{2}(2) .=35.351, p<.001\right]$. Physical demand score increased between the low and moderate difficulties $(\mathrm{Z}=3.218, \mathrm{p}=.004, \mathrm{r}=.509)$, between the moderate and high difficulties $(\mathrm{Z}=3.734 \mathrm{p}=$ $.001, \mathrm{r}=.590)$, as well as between the low and high difficulties $(\mathrm{Z}=3.930, \mathrm{p}<.001, \mathrm{r}=.621)$.

NASA TLX scale, temporal demand: For the BBT (figure 7G), manipulation of the weight increased the temporal demand score $\left[\chi^{2}(2) .=7, p=.031\right]$. Temporal demand score did not increase between the low and moderate difficulties $(\mathrm{Z}=.361, \mathrm{p}=1.000, \mathrm{r}=.057)$, as well as between the low and high difficulty $(\mathrm{Z}=1.934, \mathrm{p}=.159, \mathrm{r}=.306)$, but did between the moderate and high difficulty $(\mathrm{Z}=2.423$, $\mathrm{p}=.046, \mathrm{r}=.383$ ). For the PT (figure $8 \mathrm{G}$ ), manipulation of the weight increased the temporal demand score too $\left[\chi^{2}(2) .=8.222, \mathrm{p}=.016\right]$. Temporal demand score did not increase between the low and moderate difficulties $(\mathrm{Z}=2.042, \mathrm{p}=.123, \mathrm{r}=.323)$, as well as between the moderate and high difficulties $(Z=2.110, p=.105, r=.334)$, but did between the low and high difficulties $(Z=3.086, p$ $=.006, \mathrm{r}=.488)$. 
629

630

631

632

633

634

635

636

637

638

639

640

641

642

643

644

645

646

647

648

649

650

NASA TLX scale, effort: For the BBT (figure 7H), manipulation of the tempo increased the effort score $\left[\chi^{2}(2) .=28.353, \mathrm{p}<.001\right]$. Effort score increased between the low and moderate difficulties $(Z$ $=3.309, \mathrm{p}=.003, \mathrm{r}=.523)$, between the moderate and high difficulties $(\mathrm{Z}=3.225, \mathrm{p}=.004, \mathrm{r}=.510)$, as well as between the low and high difficulties $(\mathrm{Z}=3.798, \mathrm{p}<.001, \mathrm{r}=.601)$. For the PT (figure $8 \mathrm{H}$ ), manipulation of the tempo increased the effort score too $\left[\chi^{2}(2) .=25.507, p<.001\right]$. Effort score did not increase between the low and moderate difficulties $(Z=1.720, p=.256, r=.272)$, but did so between the moderate and high difficulties $(\mathrm{Z}=3.362, \mathrm{p}=.002, \mathrm{r}=.532)$, as well as between the low and high difficulties $(\mathrm{Z}=3.604, \mathrm{p}=.001, \mathrm{r}=.570)$. $=2.315, \mathrm{p}=.021)$.
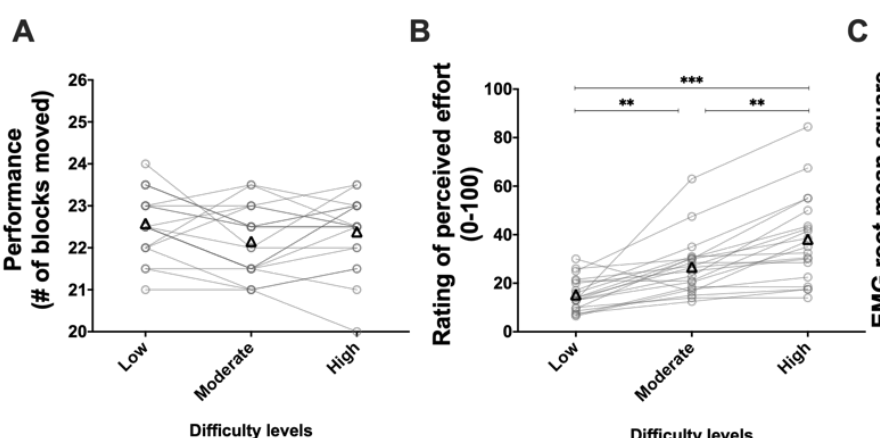

E

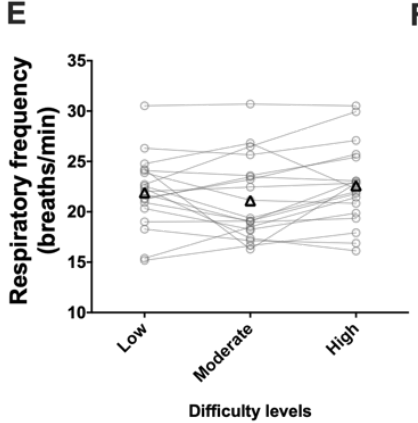

$\mathbf{F}$

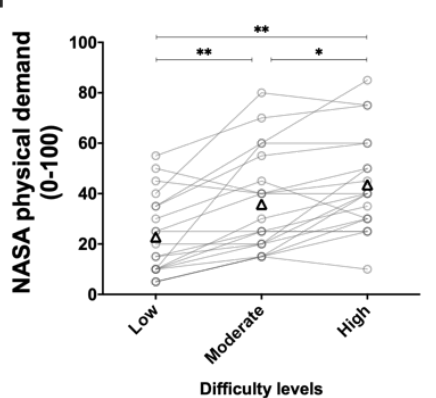

C

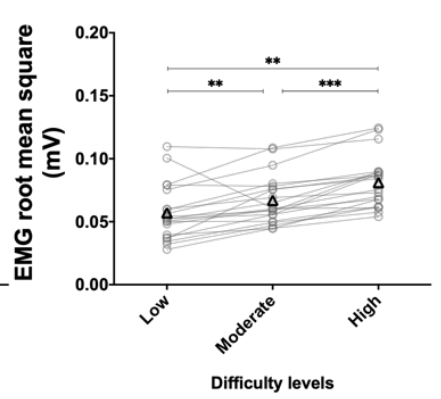

G

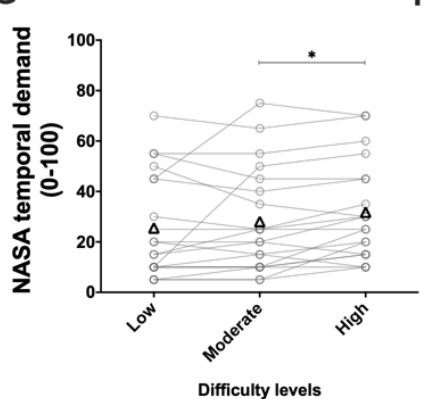

D

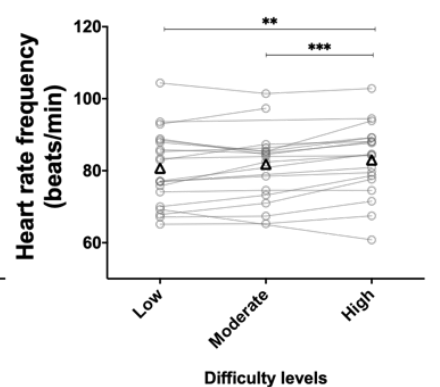

H

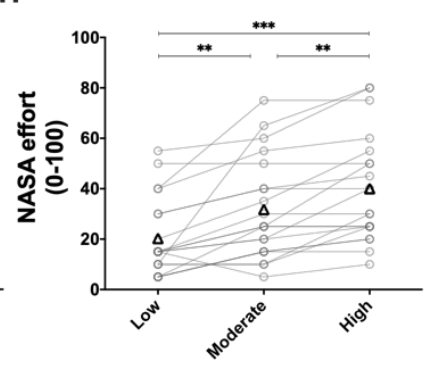

Difficulty levels

Figure 7. Experiment 1B: Adding weight on the forearm to alter task difficulty during the Box and Block test.

Effect of manipulating the weight during the Box and Block Test on performance (panel A, $\mathrm{n}=20$ ), Rating of perceived effort (panel $\mathrm{B}, \mathrm{n}=20$ ), EMG root mean square of the sum of the biceps and triceps brachial muscles (panel $\mathrm{C}, \mathrm{n}=20$ ), heart rate frequency (panel $\mathrm{D}, \mathrm{n}=16$ ), respiratory frequency (panel $\mathrm{E}, \mathrm{n}=20$ ) and NASA TLX scores for the physical demand (panel $\mathrm{F}, \mathrm{n}=20$ ), the temporal demand (panel $\mathrm{G}, \mathrm{n}=20$ ) and the subjective effort (panel $\mathrm{H}, \mathrm{n}=20$ ). Movements were performed at a fixed tempo of $0.75 \mathrm{~Hz}$. For the low difficulty, no additional weight on the forearm was added. For the 
651

652

653

654

655

656

657

658

659

660

661

662

663

664

665

666

667

668

669

670

671

672

673

674

moderate difficulty, a weight of $0.5 \mathrm{~kg}$ was added. For the high difficulty, a weight of $1 \mathrm{~kg}$ was added. Data are presented as the main effect of difficulty. The $\mathrm{n}$ indicates the number of participants with all the data in each three level of difficulties. Changes in the $\mathrm{n}$ reflects data loss due to the issue with equipment or movement artefact. Individual data are presented in grey circles and means in black triangles. * difference between two difficulty level. One symbol for $\mathrm{p}<0.05$, two symbols for $\mathrm{p}<0.01$ and three symbols for $\mathrm{p}<0.001$.
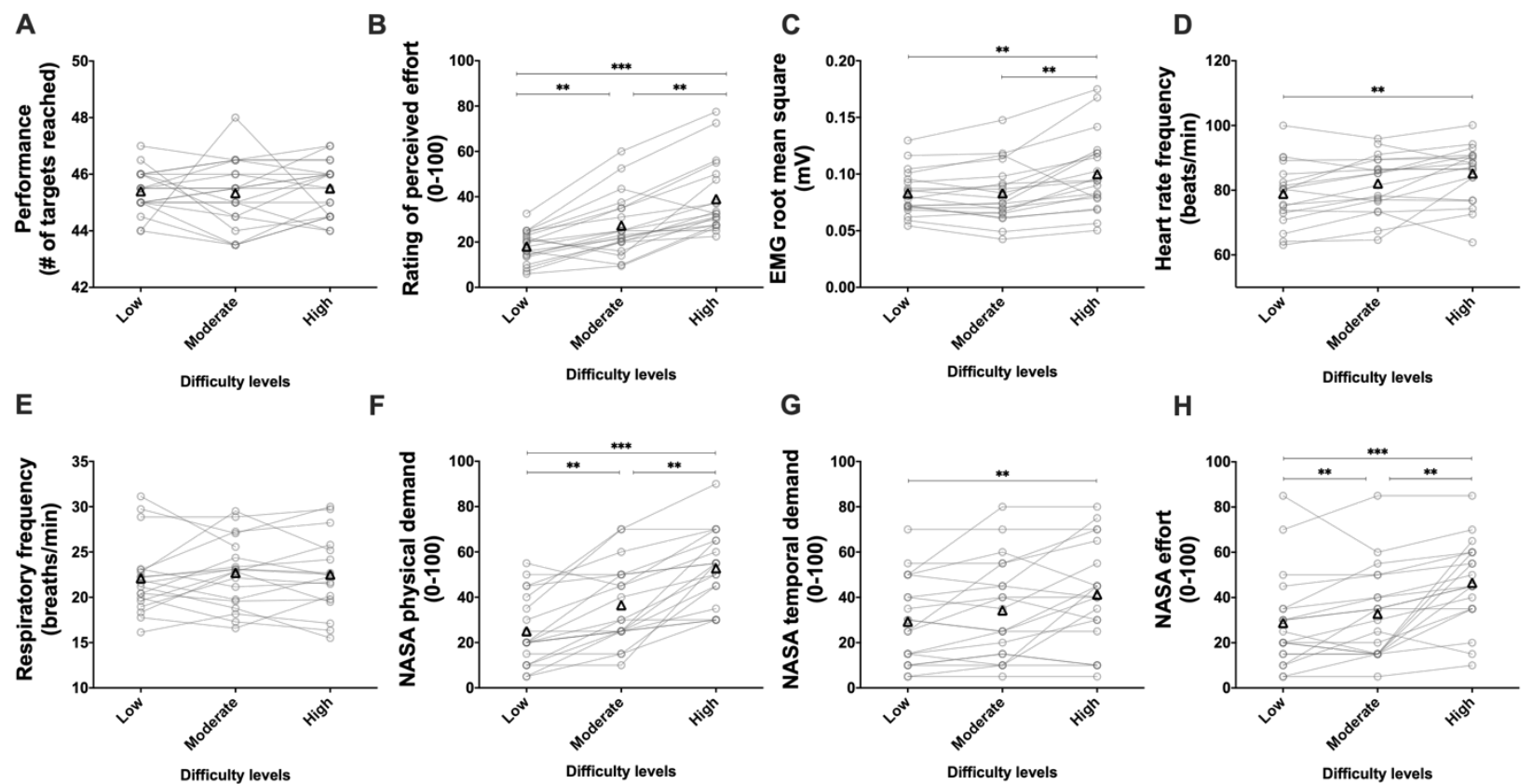

Figure 8. Experiment 1B: Adding weight on the forearm to alter task difficulty during the Pointing Task.

Effect of manipulating the weight during the Pointing Task on performance (panel A, $n=20$ ), Rating of perceived effort (panel $B, n=20$ ), EMG root mean square of the sum of the biceps and triceps brachial muscles (panel $\mathrm{C}, \mathrm{n}=20$ ), heart rate frequency (panel $\mathrm{D}, \mathrm{n}=17$ ), respiratory frequency (panel $\mathrm{E}, \mathrm{n}=20$ ) and NASA TLX scores for the physical demand (panel $\mathrm{F}, \mathrm{n}=20$ ), the temporal demand (panel $\mathrm{G}, \mathrm{n}=20$ ) and the subjective effort (panel $\mathrm{H}, \mathrm{n}=20$ ). Movements were performed at a fixed tempo of $1.5 \mathrm{~Hz}$. For the low difficulty, no additional weight on the forearm was added. For the moderate difficulty, a weight of $0.5 \mathrm{~kg}$ was added. For the high difficulty, a weight of $1 \mathrm{~kg}$ was added. Data are presented as the main effect of difficulty. The $\mathrm{n}$ indicates the number of participants with all the data in each three level of difficulties. Changes in the $\mathrm{n}$ reflects data loss due to the equipment. Individual data are presented in grey circles and means in black triangles. * difference between two difficulty level. One symbol for $\mathrm{p}<0.05$, two symbols for $\mathrm{p}<0.01$ and three symbols for $\mathrm{p}<0.001$.

\section{Experiment 2}

In this experiment, participants visited the laboratory once. In Experiment 2A, we prescribed $30 \mathrm{~s}$ of exercise with the BBT performed at four intensities of effort (light, moderate, strong and very 
675 strong). Performance, EMG RMS and heart rate frequency were monitored for each prescribed effort 676 intensity. Then, in Experiment 2B, we manipulated task difficulty (low, high) by adding two different 677 weights on the participant's dominant forearm while performing the standardized $60 \mathrm{~s} \mathrm{BBT.} \mathrm{Each} \mathrm{level}$ 678 of difficulty was repeated twice. Performance, EMG, heart rate frequency and the subjective workload 679 were measured for each repetition of each level of difficulty.

\section{a. Experiment 2A : Using the perception of effort to prescribe the exercise}

$681 \quad$ Results are presented in figure 9.

682 Performance: Increasing the prescribed effort intensity resulted in an increased performance $683\left[F(1.7,31.6)=168.560, p<.001, \eta_{\mathrm{p}}^{2}=.899\right.$; figure 9A $]$. Performance increased between the light and 684 moderate effort intensities $[\mathrm{t}(19)=11.393, \mathrm{p}<.001, \mathrm{r}=.934]$, between moderate and strong effort intensities $[\mathrm{t}(19)=12.564, \mathrm{p}<.001, \mathrm{r}=.945]$, as well as between strong and very strong effort intensities $[\mathrm{t}(19)=4.258, \mathrm{p}=.001, \mathrm{r}=.699]$.

Heart rate frequency: Increasing the prescribed effort intensity resulted in an increased heart rate $\left[F(3,57)=29.074, p<.001, \eta_{\mathrm{p}}^{2}=.605\right.$; figure 9B]. The increase in heart rate frequency between the light and moderate effort intensities did not reach significance $[\mathrm{t}(19)=2.316, \mathrm{p}=.096, \mathrm{r}=.469]$. Heart rate frequency significantly increased between the moderate and strong difficulty $[\mathrm{t}(19)=4.027, \mathrm{p}=$ $.002, \mathrm{r}=.679]$, as well as between strong and very strong effort intensities $[\mathrm{t}(19)=2.925, \mathrm{p}=.026, \mathrm{r}=$ $692 \quad .557]$.

$693 E M G R M S$ : Increasing the prescribed effort intensity resulted in an increased EMG RMS $[F(1.4$, $69426.8)=36.901, p<.001, \eta_{\mathrm{p}}^{2}=.660$; figure 9C]. EMG RMS increased between the light and moderate 695 intensities $[\mathrm{t}(19)=4.476, \mathrm{p}=.001, \mathrm{r}=.716]$, between moderate and strong effort intensities $[\mathrm{t}(19)=$ $6965.233, \mathrm{p}<.001, \mathrm{r}=.768]$, as well as between strong and very strong effort intensities $[\mathrm{t}(19)=4.310, \mathrm{p}$ $697=.001, \mathrm{r}=.703]$. 
698

699

700

701

702

703

704

705

706

707

708

709

710

711

712

713

714

715

716

717

718

719

720

721

722
A

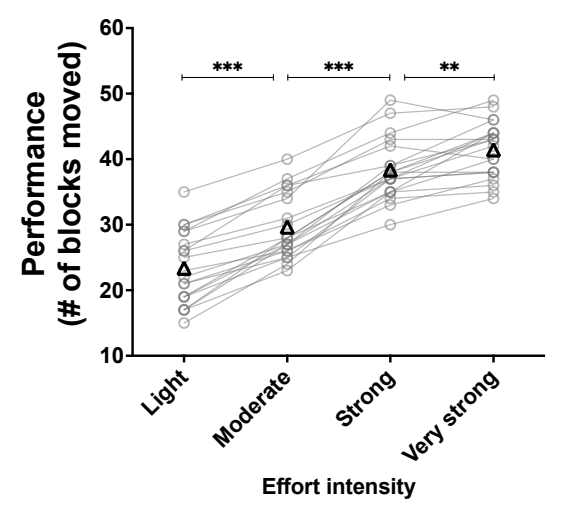

B

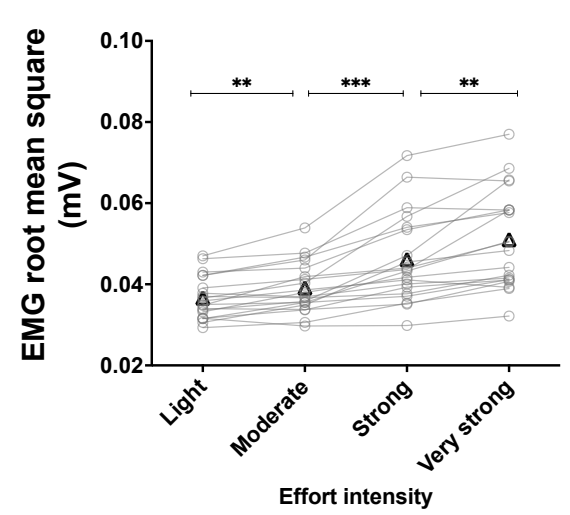

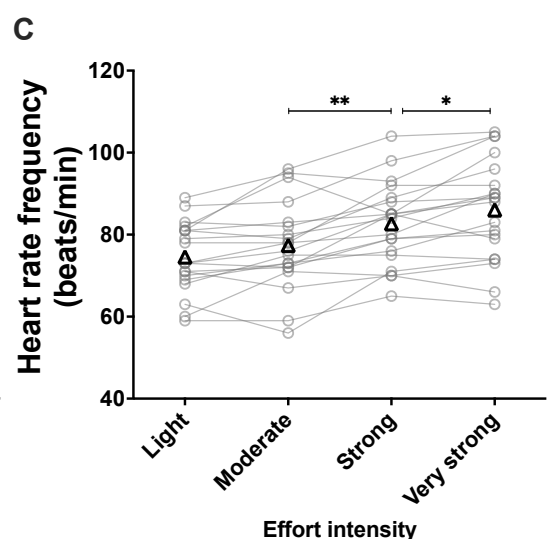

Figure 9. Experiment 2A: using the perception of effort to prescribe the exercise during the Box and Block test.

Effect of increasing the prescribed intensity of effort on performance (panel A, $n=20$ ), EMG root mean square of the sum of the biceps and triceps brachial muscles (panel $B, n=20$ ), heart rate frequency (panel $\mathrm{C}, \mathrm{n}=20$ ) during the Box and Block Test. The exercise was prescribed at four intensities of perceived effort via the CR100 scale: light (13/100), moderate (23/100), strong (50/100), very strong (70/100). Data are presented as the main effect of effort intensity. Individual data are presented in grey circles and means in black triangles. * difference between two intensities of effort. One symbol for $\mathrm{p}<0.05$, two symbols for $\mathrm{p}<0.01$ and three symbols for $\mathrm{p}<0.001$.

\section{b. Experiment 2B : Effects of adding weight on the forearm when completing the}

\section{Box and Block test with the standardized instructions.}

Results of the main effects of difficulty are presented in figure 10.

Performance: Main effect of repetition revealed a greater performance in the second repetition compared to the first repetition $\left[F(1,19)=34.836, p<.001, \eta_{\mathrm{p}}^{2}=.647\right]$. Main effect of difficulty did not reach significance $\left[F(1,19)=1.867, p=.188, \eta_{p}{ }^{2}=.090\right.$; figure $\left.10 \mathrm{~A}\right]$. The repetition $\times$ difficulty interaction reached significance $\left[F(1,19)=5.166, p=.035, \eta_{p}^{2}=.214\right]$. Follow-up tests revealed an increased performance between the first and second repetitions for both the low (from $84.3 \pm 6.6$ to $89.7 \pm 8.0 ;[\mathrm{t}(19)=5.219, \mathrm{p}<.001, \mathrm{r}=.768])$ and high (from $84.0 \pm 7.0$ to $86.8 \pm 6.9 ;[\mathrm{t}(19)=3.667$, $\mathrm{p}=.005, \mathrm{r}=.644]$ ) difficulties. Performance did not differ for the first repetition between the low and high difficulties $(84.3 \pm 6.6$ and $84.0 \pm 7.0 ;[\mathrm{t}(19)=.188, \mathrm{p}=1.000, \mathrm{r}=.043])$. During the second repetition, performance did not significantly decrease between the low and high difficulties $(89.7 \pm 8.0$ and $86.8 \pm 6.9 ;[\mathrm{t}(19)=2.316, \mathrm{p}=.096, \mathrm{r}=.469])$.

Perception of effort: Main effect of repetition revealed a higher rating of perceived effort in the second repetition compared to the first repetition $\left[F(1,19)=14.350, p=.001, \eta_{\mathrm{p}}{ }^{2}=.430\right]$. Main effect 
723 of difficulty revealed an increase in rating of perceived effort with the increase in difficulty $[F(1,19)$

$724=6.779, p=.017, \eta_{\mathrm{p}}{ }^{2}=.263$; figure $\left.10 \mathrm{~B}\right]$. The repetition $\times$ difficulty interaction did not reach 725 significance $\left[F(1,19)=.005, p=.946, \eta_{\mathrm{p}}^{2}<.001\right]$.

726 Heart rate frequency: Main effect of repetition $\left[F(1,19)=1.094, p=.309, \eta_{\mathrm{p}}^{2}=.054\right]$, difficulty $727\left[F(1,19)=.664, p=.425, \eta_{\mathrm{p}}^{2}=.034\right.$; figure $\left.10 \mathrm{C}\right]$ and repetition $\times$ difficulty interaction $[F(1,19)=$ $\left.728.492, p=.492, \eta_{\mathrm{p}}^{2}=.025\right]$ did not reach significance.

729 EMG RMS: Main effect of repetition revealed a higher EMG RMS in the second repetition 730 compared to the first repetition $\left[F(1,19)=11.692, p=.003, \eta_{\mathrm{p}}^{2}=.381\right]$. Main effect of difficulty 731 revealed an increase in EMG RMS with the increase in difficulty $\left[F(1,19)=14.280, p<.001, \eta_{\mathrm{p}}^{2}=\right.$ 732.429 ; figure $10 \mathrm{D}]$. The repetition $\times$ difficulty interaction did not reach significance $[F(1,19)=.002, p$ $\left.733=.964, \eta_{\mathrm{p}}^{2}<.001\right]$.

734 NASA TLX scale, physical demand: Main effect of repetition revealed a higher physical demand 735 score in the second repetition compared to the first repetition $\left[F(1,19)=20.328, p<.001, \eta_{\mathrm{p}}^{2}=.517\right]$.

736 Main effect of difficulty revealed an increase in physical demand score with the increase in difficulty $737\left[F(1,19)=13.426, p=.002, \eta_{\mathrm{p}}^{2}=.414\right.$; figure $\left.10 \mathrm{E}\right]$. The repetition $\times$ difficulty interaction did not 738 reach significance $\left[F(1,19)=1.342, p=.261, \eta_{\mathrm{p}}{ }^{2}=.066\right]$.

739

NASA TLX scale, effort: Main effect of repetition did not reach significance $[F(1,19)=2.664, p=$ $\left..119, \eta_{\mathrm{p}}{ }^{2}=.123\right]$. Main effect of difficulty revealed an increase in effort score with the increase in difficulty $\left[F(1,19)=8.780, p=.008, \eta_{\mathrm{p}}^{2}=.316\right.$; figure $\left.10 \mathrm{~F}\right]$. The repetition $\times$ difficulty interaction did not reach significance $\left[F(1,19)=.039, p=.846, \eta_{\mathrm{p}}^{2}=.002\right]$. 
A
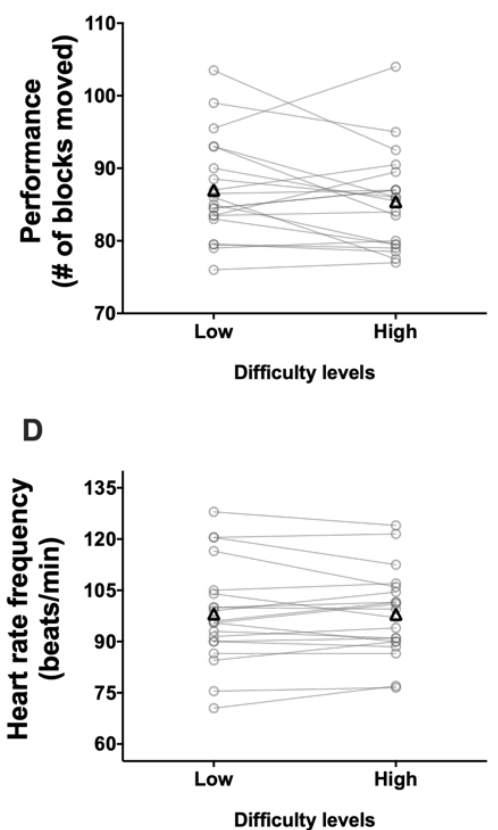

B

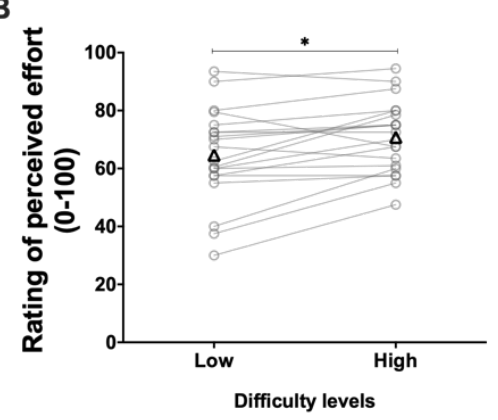

E

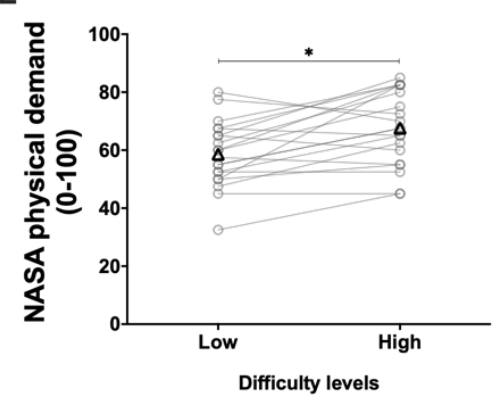

C

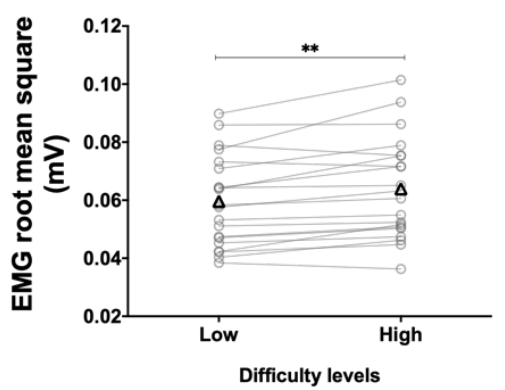

$\mathbf{F}$

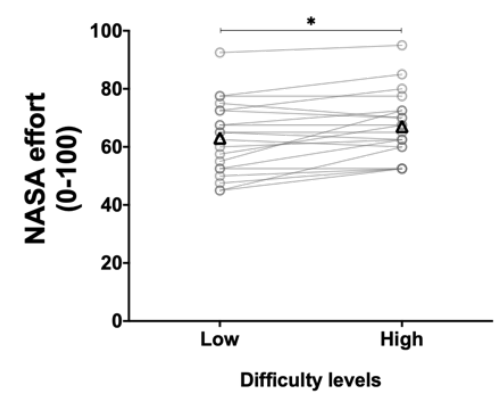

Figure 10. Experiment 2B: Adding weight on the forearm to alter task difficulty during the Box and Block test with its validated instructions.

747 Effect of weight manipulation on performance (panel A, $n=20$ ), rating of perceived effort (panel $B, n$ $748=20$ ), EMG root mean square of the sum of the biceps and triceps brachial muscles (panel $\mathrm{C}, \mathrm{n}=20$ ), 749 heart rate frequency (panel $D, n=20$ ), and NASA TLX scores for physical demand (panel $E, n=20$ ) 750 et effort (panel $\mathrm{F}, \mathrm{n}=20$ ) during the Box and Block Test with its official instructions. Data are presented 751 as the main effect of difficulty. Individual data are presented in grey circles and means in black 752 triangles. * difference between two difficulty levels. One symbol for $\mathrm{p}<0.05$, two symbols for $\mathrm{p}<$ $753 \quad 0.01$ and three symbols for $\mathrm{p}<0.001$. 


\section{Discussion}

754

755

756

757

758

759

760

761

762

763

764

765

766

767

768

769

770

771

772

773

774

775

776

777

778

779

780

781

782

783

In this study, we investigated the possibility to prescribe and monitor exercise with the perception of effort during two upper-limb motor tasks: the box and block test and a pointing task. Our results demonstrate that performance in both tasks increased when the perception of effort intensity used to prescribe the exercise increased. When the task difficulty was altered by manipulating the physical demand via different tempos or weight added on the forearm, our results demonstrate that perception of effort increased when task difficulty increased and that performance could be maintained at a cost of a higher perception of effort. This increased perception of effort was observed during both the modified version of the box and block test as well as the pointing task performed in experiment 1 . Finally, when completing the standardized version of the box and block test in the absence and presence of additional weight on the forearm, in experiment 2, we observed a maintained performance at a cost of a higher perception of effort. Overall, results from both experiments demonstrate that perception of effort can be efficiently used in healthy young adults to prescribe and monitor physical resources allocation during upper-limb motor tasks.

Perception of effort can be used to prescribe the exercise intensity of upper-limb motor tasks.

Perception of effort is widely used in the field of exercise sciences to prescribe exercise (Borg, 1998; Eston \& Parfitt, 2018). As an example, the intensity of perception of effort has been used to prescribe locomotor exercise such as running or cycling (e.g., Christian et al., 2014; Hobbins et al., 2019), and resistance exercise involving the upper and lower limb (e.g., Gearhart et al., 2009; Helms et al., 2017; Zourdos et al., 2016). However, to the best of our knowledge, the possibility to use the intensity of perception of effort for exercise prescription in the context of upper-limb motor tasks remains untested. As the intensity of effort engaged in a task is proposed to determine the performance in this task (Brehm \& Self, 1989; Richter et al., 2016), performance should increase when the intensity of perceived effort increases. We tested this possibility in both experiments. In experiment 1 , we observed during the box and block test and a pointing task a gradual increase in performance between each intensity of perceived effort used to prescribe the exercise. This observation was subsequently reproduced in experiment 2 with another sample of participants performing the regular box and block test. Therefore, as previously observed during locomotor exercise or resistance exercise, our results suggest that the intensity of perceived effort could be an efficient tool to prescribe the exercise during upper-limb motor tasks. 
To further confirm the possibility to use the perception of effort to prescribe exercise, we also

785

786

787

788

789

790

791

792

793

794

795

796

797

798

799

800

801

802

803

804

805

806

807

808

809

810

811

812

813

814

815 monitored several physiological responses to the task performed: muscle activation, heart rate and respiratory frequencies. These physiological responses are known to rise when the intensity of a task is increased during locomotor exercise as well as resistance exercise (de Morree \& Marcora, 2010, 2012; Eston \& Parfitt, 2018); we therefore hypothesized that the physiological responses would rise with the increased perceived effort intensity. As expected, all physiological parameters rose with the increased exercise intensity, confirming an increase in physical resources involved in the upper-limb motor tasks performed when the prescribed perceived effort intensity increased. However, it is crucial to note that solely the muscle activation gradually increased between each prescribed perceived effort intensity. In experiment 1, our planed follow-up tests on the main effect of effort intensity failed to reveal a significant increase in respiratory frequency between each intensity. These tests also revealed that heart rate frequency solely increased between the intensities moderate - strong, and not between the intensities light - moderate and strong - very strong. As upper-limb motor tasks involve a lower muscle mass than locomotor exercise or resistance exercise and increasing the muscle mass involved in a task is known to increase cardiorespiratory responses to the exercise (MacInnis et al., 2017; Sidhu et al., 2013), the lack of observed increase between intensities in heart rate frequency and respiratory frequency in our study may be due to the low muscle mass involved in the tasks performed. In experiment 2, we used a chest belt to better control for movement artifact and increasing the quality of our heart rate frequency measurement. Using the chest belt, compared to the finger pulse transducer, allowed us to avoid data loss and capture an increased heart rate frequency between the intensities moderate - strong and strong - very strong, but not between the intensities light - moderate. Consequently, by integrating the two experiments, our results suggest that when prescribing the exercise during upper-limb motor tasks with the intensity of perceived effort, researchers and clinicians should prioritize the use of EMG over heart rate and respiratory frequencies to monitor physiological changes in the physical resources engaged in the task. During upper-limb tasks, perception of effort would seem more sensitive than heart rate frequency or respiratory frequency.

\section{Perception of effort changes with the manipulation of physical demand}

Perception of effort is not only used to prescribe the exercise, but also to monitor the exercise (Borg, 1998; Eston \& Parfitt, 2018). Indeed, the intensity of perception of effort during a motor task has been extensively shown to be responsive to changes in task difficulty imposed by various experimental manipulations. As an example, perception of effort is altered by the intensity of muscle 
816 contraction (e.g., de Morree \& Marcora, 2010, 2012), the presence of muscle or mental fatigue (e.g.,

817 Jacquet et al., 2021; Pageaux \& Lepers, 2016; Pageaux \& Lepers, 2018) or changes in environmental

818 conditions (e.g., Borg et al., 2018; Girard \& Racinais, 2014; Jeffries et al., 2019). In our study, to test

819 the possibility to monitor the exercise intensity during upper-limb motor tasks, we altered task

820 difficulty by manipulating the physical demand of the tasks performed via imposing various movement

821 tempos or adding weight on the forearm. We expected the perception of effort to raise with task

822 difficulty, regardless of the type of physical demand manipulation used.

823 In experiment 1, during the tempo session, we manipulated the task physical demand by 824 imposing three different movement speeds to complete the box and block test and pointing task. The 825 increased number of blocks moved during the box and block test and targets reached during the 826 pointing task confirmed that we were successful in our experimental manipulation. We observed an 827 increased perception of effort between each task difficulty, suggesting the possibility to track changes 828 in task difficulty imposed by changes in movement speed during upper-limb motor tasks. This 829 increased perception of effort was associated with consistent increased muscle activation and heart rate 830 frequency during both tasks. During the weight session, we manipulated the task physical demand by 831 adding weights on the forearm and imposing a single movement tempo to constrain performance across 832 task difficulties. The lack of changes in performance in both tasks across difficulties confirms that we 833 were successful in our experimental manipulation. In line with the motivational intensity theory 834 (Brehm \& Self, 1989; Richter et al., 2016), when task difficulty increases, performance could be 835 maintained by increasing the effort invested in the task. This proposed mechanism to maintain 836 performance is verified in our experiment via the increased perception of effort intensity between each 837 task difficulty, suggesting the possibility to track changes in task difficulty imposed by manipulating 838 the weight of the exercising forearm moved during upper-limb motor tasks. The increased muscle 839 activation and heart rate frequency over task difficulties further support the mechanism proposed by 840 the motivational intensity theory. However, it noticeable that muscle activation did not increase in the 841 pointing task between the easy - medium difficulties, and solely between the medium - hard 842 difficulties. This lack of changes when increasing the difficulty from no additional weight on the 843 forearm (easy difficulty) to a light additional weight on the forearm ( $0.5 \mathrm{k}$, medium difficulty) is most 844 likely due to the recruitment of other muscle groups than the elbow flexor-extensors to compensate for 845 this specific increase in difficulty.

846 In experiment 2, we performed the standardized version of the box and block test by adding a 847 weight on the forearm to increase task difficulty. Neither performance nor movement speed was 
848

849

850

851

852

853

854

855

856

857

858

859

860

861

862

863

864

865

866

867

868

869

870

871

872

873

874

875

876

877

878

controlled, the participants had to move as many blocks as possible in $60 \mathrm{~s}$. In this specific experimental paradigm, the motivational intensity theory would predict two possible outcomes (Brehm \& Self, 1989; Richter et al., 2016) : i) performance will drop if the increase in task difficulty is beyond the participants capacity, or ii) performance will be maintained if the increase in task difficulty is within the participants capacity, and this maintained performance will be possible at a cost of a higher effort invested in the task. As our participants were young and healthy, and the weight added on the forearm was chosen following pilot experiments aiming to limit the development of fatigue, we expected that our participants would be able to maintain performance by increasing the effort invested in the task. In line with our hypothesis performance did not differ between the easy and hard difficulty, and the maintained performance was associated with an increased rating of perceived effort reported by the participants. This increase in perception of effort was associated with increased muscle activation, as observed in experiment 1 to compensate for the heavier forearm to move during the box and block test.

Interestingly, not all the physiological variables monitored were responsive to changes in task difficulty in both experiments. In experiment 1 , the respiratory frequency did not increase between the difficulties easy - medium in both tasks when the physical demand was manipulated with the tempo, and no main effect of task difficulty was observed on respiratory frequency when the physical demand was manipulated with the addition of weight on the forearm. Regarding heart rate frequency, changes in this variable between each difficulty were consistently observed only when the task difficulty was manipulated with the tempo. Furthermore, the increased perception of effort observed in experiment 2 to maintain performance during the box and block test performed with the standardized instructions did not occur in the presence of increased heart rate frequency. These results extend the previous observation of the lack of changes in heart rate frequency and respiratory frequency when the intensity of perceived effort is used to prescribe the exercise and confirm that neither heart rate nor respiratory frequency can be used as an efficient physiological correlate of perception of effort in the context of upper-limb motor tasks. Additionally, it is important to note that we systematically monitored the perceived workload of each task at each difficulty by using the NASA-TLX scale, a validated tool used to monitor perceived workload in various contexts (Hart, 2006; Hart \& Staveland, 1988). While this scale captured most manipulations of the physical demand performed in both experiments, a lack of changes in the physical demand score, temporal demand score or effort score was observed in some experimental conditions. Therefore, our results suggest that monitoring of perception of effort with category ratio scales as we did in this study could be a complementary approach for researchers in 
879

880

881

882

883

884

885

886

887

888

889

890

891

892

893

894

895

896

897

898

899

900

901

902

903

904

905

906

907

908

909

human factors interested in capturing fine changes in perceived workload when task difficulty is manipulated.

\section{Integration with the neurophysiology of perception of effort}

While our experiment did not aim to investigate the neurophysiology of perception of effort, the changes (or lack of changes) in the physiological variables monitored during both experiments allow us to reconcile our results with existing theories on the neurophysiology of perception of effort in the context of motor tasks (de Morree \& Marcora, 2015; Pageaux, 2016). In brief, while there is an ongoing debate on the sensory signal(s) generating perception of effort (Amann \& Light, 2014; Broxterman et al., 2018; Marcora, 2009; Pageaux, 2016; Smirmaul, 2014; Steele \& Fisher, 2018), accumulating evidence suggest that when effort perception is investigated as a sensation dissociated from other exercise-related sensations (e.g., pain or discomfort), perception of effort is generated by the neuronal process of the corollary discharge associated with the central motor command and not by afferent feedback from the working muscles and organs (de Morree et al., 2012; de Morree \& Marcora, 2015; Marcora, 2009; Pageaux \& Gaveau, 2016). Our results are consistent with this corollary discharge model of perception of effort. Indeed, muscle activation measured with EMG is traditionally used as a marker of the central motor command (Carrier et al., 2011; Gaveau et al., 2021; Kozlowski et al., 2021; Thoroughman \& Shadmehr, 1999), and among the three physiological variables measured, only muscle activation was able to track the changes in perception of effort across manipulations of task difficulties and prescription of exercise via the intensity of this perception. Furthermore, in line with the corollary discharge model of perception of effort and the traditional use of this perception as a marker of the central motor command (Jacquet et al., 2021; Kjær et al., 1999; Kozlowski et al., 2021; McCloskey et al., 1974; Mitchell et al., 1989; Seed et al., 2019), our results should motivate the monitoring of this perception in various population with impaired motor control such as older adults (Carment et al., 2018), stroke patients (Neva et al., 2019), Parkinson patients (Sacheli et al., 2019) or other populations with neurological disorders. Future studies should replicate our results with such populations and explore how this perception in the context of specific upper-limb motor tasks is impaired in comparison to healthy individuals. Such studies could provide interesting insights into this perception by further validating its use as a marker of the central motor command in various populations, and potentially open new possibilities in rehabilitation and testing of capacities. 
911 While our results provide strong support in favor of the use of perception of effort to prescribe

912 and monitor the exercise in the context of upper-limb motor tasks, we have to acknowledge some

913 limitations to be considered for futures studies. Despite our attempt to control for the induction of

914 fatigue, subjective feelings of fatigue slightly increased in the weight session of experiment $1(+0.9$

$915+/-1.5$ on a visual analog scale). However, as the completion of the box and block test and the pointing

916 task, as well as the difficulties, were randomized, we are confident that this slight increase in fatigue

917 did not impact the validity of our results. Nonetheless, future studies using physical demand

918 manipulations and controlling for the presence of fatigue should consider increasing the recovery

919 period between each task completion. In this study, we focused on the box and block test as well as a

920 pointing task, and our results should be extended to other upper-limb tasks routinely used in research

921 and clinical settings with a stronger focus on manual dexterity such as the Purdue pegboard test

922 (Backman et al., 1992; Shahar et al., 1998) or the Minnesota manual dexterity test (Cederlund, 2009;

923 Lourenção et al., 2005). To conclude, the present study provides strong evidence in favor of the use of

924 the perception of effort to prescribe and monitor the exercise in the context of upper-limb motor tasks.

925 By integrating the results of the two experiments, measurement of muscle activation seems to be the 926 best physiological correlate of perception of effort during upper-limb motor tasks when the physical

927 demand of the task is manipulated. As effort is perceived not only in the physical domain but also in

928 the mental domain (Inzlicht et al., 2018; Pageaux, 2016; Preston, 2009), future studies should test the possibility to extend our results in the context of the manipulation of the mental demand.

930

931

932 


\section{Author contributions}

934 AC, BP, JG, MPG and PR designed the study. AC, CFB and MPG conducted the experiments. AC, 935 BP, JG and MPG contributed to the data analysis. MP and BP created the figures. MPG created the 936 first draft of the manuscript. All authors edited and/or approved the final version.

\section{Funding}

938 MP was supported by a MSc scholarship from the Centre de recherche de l'Institut universitaire de 939 gériatrie de Montréal (CRIUGM) and internal scholarship from the Université de Montréal. This study

940 has been funded by the grant "Programme d'appui à des projets de recherche stratégiques et 941 structurants (PRSS)” as well as BP's CRIUGM and Université de Montréal start-up funding.

\section{Conflict of interest and data availability}

943 The authors declare that the research was conducted in the absence of any commercial or financial

944 relationships that could be construed as a potential conflict of interest. Individual data are presented 945 within the manuscript figures.

946

947 


\section{References}

948

949

950

951

952

953

954

955

956

957

958

959

960

961

962

963

964

965

966

967

968

969

970

971

972

973

974

975

976

977

978

979

980

981

982

983

984

985

Amann, M., \& Light, A. R. (2014). Reply: To PMID 24142455. Experimental physiology, 99(5), 836-836.

Au, J. S., Totosy, D. E. Z. J. O., \& Macdonald, M. J. (2017, Jun). Modeling Perceived Exertion during Graded Arm Cycling Exercise in Spinal Cord Injury. Medicine and science in sports and exercise, 49(6), 1190-1196. https://doi.org/10.1249/MSS.0000000000001203

Azevedo, A. d., Matos, L. F. d., Nakamura, F. Y., \& Pereira, G. (2016). Perception of effort monitors internal load during compounded circuit training. Motriz: Revista de Educação Física, 22, 9093. http://www.scielo.br/scielo.php?script=sci_arttext\&pid=S1980$\underline{65742016000100090 \& n r m=\text { iso }}$

Backman, C., Gibson, S. C. D., \& Parsons, J. (1992, 1992/10/01). Assessment of Hand Function: The Relationship between Pegboard Dexterity and Applied Dexterity. Canadian Journal of Occupational Therapy, 59(4), 208-213. https://doi.org/10.1177/000841749205900406

Barhorst, E. E., Andrae, W. E., Rayne, T. J., Falvo, M. J., Cook, D. B., \& Lindheimer, J. B. (2020, Jun 15). Elevated Perceived Exertion in People with Myalgic Encephalomyelitis/Chronic Fatigue Syndrome and Fibromyalgia: A Meta-analysis. Medicine and science in sports and exercise. https://doi.org/10.1249/MSS.0000000000002421

Borg, D. N., Stewart, I. B., Costello, J. T., Drovandi, C. C., \& Minett, G. M. (2018, Oct 1). The impact of environmental temperature deception on perceived exertion during fixed-intensity exercise in the heat in trained-cyclists. Physiol Behav, 194, 333-340.

https://doi.org/10.1016/j.physbeh.2018.06.026

Borg, G. (1998). Borg's perceived exertion and pain scales. Human Kinetics.

Brehm, J. W., \& Self, E. A. (1989). The intensity of motivation. Annual Review of Psychology, 40, 109-131. https://doi.org/10.1146/annurev.ps.40.020189.000545

Broxterman, R. M., Hureau, T. J., Layec, G., Morgan, D. E., Bledsoe, A. D., Jessop, J. E., Amann, M., \& Richardson, R. S. (2018). Influence of group III/IV muscle afferents on small muscle mass exercise performance: a bioenergetics perspective. The Journal of Physiology, 596(12), 2301-2314. https://doi.org/10.1113/JP275817

Carment, L., Abdellatif, A., Lafuente-Lafuente, C., Pariel, S., Maier, M. A., Belmin, J., \& Lindberg, P. G. (2018). Manual Dexterity and Aging: A Pilot Study Disentangling Sensorimotor From

PREPRINT version 2021/07/11, submitted for peer review 
986

987

988

989

990

991

992

993

994

995

996

997

998

999

1000

1001

1002

1003

1004

1005

1006

1007

1008

1009

1010

1011

1012

1013

1014

1015

1016

1017

1018

1019

1020

1021

1022

1023

1024

1025

Cognitive Decline. Frontiers in neurology, 9, 910-910.

https://doi.org/10.3389/fneur.2018.00910

Carrier, D. R., Anders, C., \& Schilling, N. (2011). The musculoskeletal system of humans is not tuned to maximize the economy of locomotion. Proceedings of the National Academy of Sciences, 108(46), 18631-18636. https://doi.org/10.1073/pnas.1105277108

Cederlund, R. (2009, 07/12). The Use of Dexterity Tests in Hand Rehabilitation. Scandinavian Journal of Occupational Therapy, 2, 99-104. https://doi.org/10.3109/11038129509106801

Christian, R., Bishop, D., GIRARD, O., \& Billaut, F. (2014, 2014-March-31). The role of sense of effort on self-selected cycling power output [Original Research]. Frontiers in Physiology, 5(115). https://doi.org/10.3389/fphys.2014.00115

Cohen, J. (1988). Statistical power analysis for the behavioural sciences (Vol. null).

Cook, D. B., O'Connor, P. J., Lange, G., \& Steffener, J. (2007, May 15). Functional neuroimaging correlates of mental fatigue induced by cognition among chronic fatigue syndrome patients and controls [Research Support, Non-U.S. Gov't

Research Support, U.S. Gov't, Non-P.H.S.]. Neuroimage, 36(1), 108-122. https://doi.org/10.1016/j.neuroimage.2007.02.033

Cos, I. (2017). Perceived effort for motor control and decision-making. PLOS Biology, 15(8), e2002885-e2002885. https://doi.org/10.1371/journal.pbio.2002885

de Morree, H. M., Klein, C., \& Marcora, S. (2012). Perception of effort reflects central motor command during movement execution. Psychophysiology, 49(9), 1242-1253. https://doi.org/10.1111/j.1469-8986.2012.01399.x

de Morree, H. M., Klein, C., \& S., M. (2014). Cortical substrates of the effects of caffeine and timeon-task on perception of effort. Journal of Applied Physiology, 117(12), 1514-1523. https://doi.org/10.1152/japplphysiol.00898.2013

de Morree, H. M., \& Marcora, S. (2010, 2010/12/01/). The face of effort: Frowning muscle activity reflects effort during a physical task. Biological Psychology, 85(3), 377-382. https://doi.org/https://doi.org/10.1016/j.biopsycho.2010.08.009

de Morree, H. M., \& Marcora, S. (2012, 2012/05/01). Frowning muscle activity and perception of effort during constant-workload cycling. European Journal of Applied Physiology, 112(5), 1967-1972. https://doi.org/10.1007/s00421-011-2138-2

PREPRINT version 2021/07/11, submitted for peer review 
de Morree, H. M., \& Marcora, S. (2015, 09/01). Psychobiology of Perceived Effort During Physical Tasks. 255-270. https://doi.org/10.1007/978-1-4939-1236-0_17

Décombe, A., Brunel, L., Capdevielle, D., \& Raffard, S. (2020, Jul). Too much or too little? Exploring effort perception in schizophrenia within the framework of motivational intensity theory. Cogn Neuropsychiatry, 25(4), 312-327. https://doi.org/10.1080/13546805.2020.1798220

Enoka, R. M., \& Stuart, D. G. (1992, May). Neurobiology of muscle fatigue. Journal of applied physiology, 72(5), 1631-1648. http://www.ncbi.nlm.nih.gov/pubmed/1601767

Eston, R., \& Parfitt, G. (2018). Perceived Exertion, Heart Rate, and other Non-Invasive Methods for Exercise Testing and Intensity Control. In (pp. 464-499). https://doi.org/10.4324/9781315385662-18

Faelli, E., Ferrando, V., Bisio, A., Ferrando, M., Torre, A., Panasci, M., \& Ruggeri, P. (2019, Sep). Effects of Two High-intensity Interval Training Concepts in Recreational Runners. Int J Sports Med, 40(10), 639-644. https://doi.org/10.1055/a-0964-0155

Fernandez, C., Firdous, S., Jehangir, W., Behm, B., Mehta, Z., Berger, A., \& Davis, M. (2020, Jan). Cancer-Related Fatigue: Perception of Effort or Task Failure? Am J Hosp Palliat Care, 37(1), 34-40. https://doi.org/10.1177/1049909119849420

Field, A. (2005). Discovering statistics using SPSS, 2nd ed. Sage Publications, Inc.

Flairty, J. E., \& Scheadler, C. M. (2020). Perceived and Heart Rate-based Intensities during Selfpaced Walking: Magnitudes and Comparison. International journal of exercise science, 13(5), 677-688. https://pubmed.ncbi.nlm.nih.gov/32509131

1055 https://www.ncbi.nlm.nih.gov/pmc/articles/PMC7241645/

Gaveau, J., Grospretre, S., Berret, B., Angelaki, D., \& Papaxanthis, C. (2021, 04/01). A cross-species neural integration of gravity for motor optimization. Science Advances, 7, eabf7800. https://doi.org/10.1126/sciadv.abf7800

Gearhart, R. F. J., Lagally, K. M., Riechman, S. E., Andrews, R. D., \& Robertson, R. J. (2009). Strength Tracking Using the OMNI Resistance Exercise Scale in Older Men and Women. The Journal of Strength \& Conditioning Research, 23(3), 1011-1015. https://doi.org/10.1519/JSC.0b013e3181a2ec41 
1066

1067

1068

1069

1070

1071

1072

1073

1074

1075

1076

1077

1078

1079

1080

1081

1082

1083

1084

1085

1086

1087

1088

1089

1090

1091

1092

1093

1094

1095

1096

1097

1098

1099

1100

1101

1102

1103

1104

1105

Girard, O., \& Racinais, S. (2014). Combining heat stress and moderate hypoxia reduces cycling time to exhaustion without modifying neuromuscular fatigue characteristics. European Journal of Applied Physiology, 114(7), 1521-1532. https://doi.org/10.1007/s00421-014-2883-0

Hart, S. G. (2006, 2006/10/01). Nasa-Task Load Index (NASA-TLX); 20 Years Later. Proceedings of the Human Factors and Ergonomics Society Annual Meeting, 50(9), 904-908. https://doi.org/10.1177/154193120605000909

Hart, S. G., \& Staveland, L. E. (1988). Development of NASA-TLX (Task Load Index): Results of Empirical and Theoretical Research. In P. A. Hancock \& N. Meshkati (Eds.), Advances in Psychology (Vol. 52, pp. 139-183). North-Holland. https://doi.org/https://doi.org/10.1016/S0166-4115(08)62386-9

Helms, E. R., Brown, S. R., Cross, M. R., Storey, A., Cronin, J., \& Zourdos, M. C. (2017, Oct). SelfRated Accuracy of Rating of Perceived Exertion-Based Load Prescription in Powerlifters. $J$ Strength Cond Res, 31(10), 2938-2943. https://doi.org/10.1519/jsc.0000000000002097

Hobbins, L., Gaoua, N., Hunter, S., \& Girard, O. (2019, 2019/10/01/). Psycho-physiological responses to perceptually-regulated interval runs in hypoxia and normoxia. Physiology \& Behavior, 209, 112611. https://doi.org/https://doi.org/10.1016/j.physbeh.2019.112611

Horstman, D. H., Morgan, W. P., Cymerman, A., \& Stokes, J. (1979, Jun). Perception of effort during constant work to self-imposed exhaustion. Percept Mot Skills, 48(3 Pt 2), 1111-1126. https://doi.org/10.2466/pms.1979.48.3c.1111

Impellizzeri, F. M., Rampinini, E., Coutts, A. J., Sassi, A., \& Marcora, S. M. (2004, Jun). Use of RPE-based training load in soccer. Medicine and science in sports and exercise, 36(6), 10421047. https://doi.org/10.1249/01.mss.0000128199.23901.2f

Inzlicht, M., Shenhav, A., \& Olivola, C. Y. (2018, Apr). The Effort Paradox: Effort Is Both Costly and Valued. Trends Cogn Sci, 22(4), 337-349. https://doi.org/10.1016/j.tics.2018.01.007

Izawa, J., Rane, T., Donchin, O., \& Shadmehr, R. (2008, 04/01). Motor Adaptation as a Process of Reoptimization. The Journal of neuroscience : the official journal of the Society for Neuroscience, 28, 2883-2891. https://doi.org/10.1523/JNEUROSCI.5359-07.2008

Izawa, J., \& Shadmehr, R. (2008). On-Line Processing of Uncertain Information in Visuomotor Control. The Journal of Neuroscience, 28(44), 11360-11368. https://doi.org/10.1523/jneurosci.3063-08.2008 
1106

1107

1108

1109

1110

1111

1112

1113

1114

1115

1116

1117

1118

1119

1120

1121

1122

1123

1124

1125

1126

1127

1128

1129

1130

1131

1132

1133

1134

1135

1136

1137

1138

1139

1140

1141

1142

1143

1144

1145

Jacquet, T., Lepers, R., Poulin-Charronnat, B., Bard, P., Pfister, P., \& Pageaux. (2021, Jan 8). Mental fatigue induced by prolonged motor imagery increases perception of effort and the activity of motor areas. Neuropsychologia, 150, 107701. https://doi.org/10.1016/j.neuropsychologia.2020.107701

Jeffries, O., Patterson, S. D., \& Waldron, M. (2019, May). The effect of severe and moderate hypoxia on exercise at a fixed level of perceived exertion. Eur J Appl Physiol, 119(5), 1213-1224. https://doi.org/10.1007/s00421-019-04111-y

Kjær, M., Hanel, B., Worm, L., Perko, G., Lewis, S. F., Sahlin, K., Galbo, H., \& Secher, N. H. (1999). Cardiovascular and neuroendocrine responses to exercise in hypoxia during impaired neural feedback from muscle. American Journal of Physiology-Regulatory, Integrative and Comparative Physiology, 277(1), R76-R85.

Kozlowski, B., Pageaux, B., Hubbard, E. F., St. Peters, B., Millar, P. J., \& Power, G. A. (2021). Perception of effort during an isometric contraction is influenced by prior muscle lengthening or shortening. bioRxiv, 2021.2003.2029.437599. https://doi.org/10.1101/2021.03.29.437599

Kuppuswamy, A., Clark, E. V., Turner, I. F., Rothwell, J. C., \& Ward, N. S. (2015, Jan). Post-stroke fatigue: a deficit in corticomotor excitability? Brain : a journal of neurology, 138(Pt 1), 136148. https://doi.org/10.1093/brain/awu306

Lourenção, M., Battistella, L., Martins, L., \& Litvoc, J. (2005, 04/01). Analysis of the results of functional electric stimulation on hemiplegic patients' upper extremities using the Minnesota manual dexterity test. International journal of rehabilitation research. Internationale Zeitschrift für Rehabilitationsforschung. Revue internationale de recherches de réadaptation, 28, 25-31. https://doi.org/10.1097/00004356-200503000-00004

Luu, B. L., Smith, J. L., Martin, P. G., McBain, R. A., Taylor, J. L., \& Butler, J. E. (2016). Feedforward consequences of isometric contractions: effort and ventilation. Physiological reports, 4(15), e12882. https://doi.org/10.14814/phy2.12882

Macdonald, J. H., Fearn, L., Jibani, M., \& Marcora, S. M. (2012, Dec). Exertional fatigue in patients with CKD. Am J Kidney Dis, 60(6), 930-939. https://doi.org/10.1053/j.ajkd.2012.06.021

MacInnis, M. J., Morris, N., Sonne, M. W., Zuniga, A. F., Keir, P. J., Potvin, J. R., \& Gibala, M. J. (2017, Jul). Physiological responses to incremental, interval, and continuous counterweighted single-leg and double-leg cycling at the same relative intensities. Eur J Appl Physiol, 117(7), 1423-1435. https://doi.org/10.1007/s00421-017-3635-8 
1146

1147

1148

1149

1150

1151

1152

1153

1154

1155

1156

1157

1158

1159

1160

1161

1162

1163

1164

1165

1166

1167

1168

1169

1170

1171

1172

1173

1174

1175

1176

1177

1178

1179

1180

1181

1182

1183

1184

1185

Maikala, R. V., \& Bhambhani, Y. N. (2006, Jun). Comparisons of physiological and perceptual responses in healthy men and women during standardized arm cranking and task-specific pushing-pulling. Int Arch Occup Environ Health, 79(6), 509-520. https://doi.org/10.1007/s00420-005-0076-1

Makofske, B. (2011). Manual Dexterity. In J. S. Kreutzer, J. DeLuca, \& B. Caplan (Eds.), Encyclopedia of Clinical Neuropsychology (pp. 1522-1523). Springer New York. https://doi.org/10.1007/978-0-387-79948-3_1460

Marcora, S. (2009, Jun). Perception of effort during exercise is independent of afferent feedback from skeletal muscles, heart, and lungs. J Appl Physiol (1985), 106(6), 2060-2062. https://doi.org/10.1152/japplphysiol.90378.2008

Marcora, S. (2015, Oct 26). Can doping be a good thing? Using psychoactive drugs to facilitate physical activity behaviour. Sports medicine. https://doi.org/10.1007/s40279-015-0412-x

Marcora, S. (2019). Psychobiology of fatigue during endurance exercise. In C. Meijen (Ed.), Endurance Performance in Sport: Psychological theory and interventions (pp. 248). Routledge Taylor\&Francis Group. https://doi.org/https://doi.org/10.4324/9781315167312

Marcora, S. M. (2010). Effort: perception of. In E. B. Goldstein (Ed.), Encyclopedia of Perception (pp. 380-383). SAGE Publications Inc.

Mathiowetz, V. G., Kashman N., Weber K. (1985). Adult Norills for the Box and Block Test of Manual Dexterity. The American Journal of Occupational Therapy, 39, 386-391.

McCloskey, D. I., Ebeling, P., \& Goodwin, G. M. (1974, 1974/01/01/). Estimation of weights and tensions and apparent involvement of a "sense of effort". Experimental Neurology, 42(1), 220-232. https://doi.org/https://doi.org/10.1016/0014-4886(74)90019-3

Meir, G., Hutchinson, J. C., Habeeb, C. M., Boiangin, N. M., Shaffer, C., Basevitch, I., \& Tenenbaum, G. (2015, 2015/10/02). Are the Measurements of Attention Allocation and Perceived Exertion Trustworthy? Measurement in Physical Education and Exercise Science, 19(4), 167-176. https://doi.org/10.1080/1091367X.2015.1061531

Miller, P. C., Hall, E. E., Chmelo, E. A., Morrison, J. M., DeWitt, R. E., \& Kostura, C. M. (2009, Mar). The influence of muscle action on heart rate, RPE, and affective responses after upperbody resistance exercise. $J$ Strength Cond Res, 23(2), 366-372.

https://doi.org/10.1519/JSC.0b013e31818548f6 
Mitchell, J., Reeves Jr, D., Rogers, H., \& Secher, N. (1989). Epidural anaesthesia and cardiovascular responses to static exercise in man. The Journal of Physiology, 417(1), 13-24.

Morel, P., Ulbrich, P., \& Gail, A. (2017). What makes a reach movement effortful? Physical effort discounting supports common minimization principles in decision making and motor control. PLOS Biology, 15(6), e2001323. https://doi.org/10.1371/journal.pbio.2001323

Myers, J., Atwood, J. E., Sullivan, M., Forbes, S., Friis, R., Pewen, W., \& Froelicher, V. (1987). Perceived exertion and gas exchange after calcium and beta-blockade in atrial fibrillation. Journal of Applied Physiology, 63(1), 97-104. https://doi.org/10.1152/jappl.1987.63.1.97

Neva, J. L., Brown, K. E., Wadden, K. P., Mang, C. S., Borich, M. R., Meehan, S. K., \& Boyd, L. A. (2019). The effects of five sessions of continuous theta burst stimulation over contralesional sensorimotor cortex paired with paretic skilled motor practice in people with chronic stroke. Restor Neurol Neurosci, 37(3), 273-290. https://doi.org/10.3233/rnn-190916

Oldfield, R. C. (1971, 1971/03/01/). The assessment and analysis of handedness: The Edinburgh inventory. Neuropsychologia, 9(1), 97-113. https://doi.org/https://doi.org/10.1016/00283932(71)90067-4

Otto, A., Emery, K., \& Côté, J. N. (2019, Aug 7). Sex differences in perceptual responses to experimental pain before and after an experimental fatiguing arm task. Biol Sex Differ, 10(1), 39. https://doi.org/10.1186/s13293-019-0253-7

Pageaux. (2014, 2014/09/01). The Psychobiological Model of Endurance Performance: An EffortBased Decision-Making Theory to Explain Self-Paced Endurance Performance. Sports Medicine, 44(9), 1319-1320. https://doi.org/10.1007/s40279-014-0198-2

Pageaux. (2016, Nov). Perception of effort in Exercise Science: Definition, measurement and perspectives. Eur J Sport Sci, 16(8), 885-894. https://doi.org/10.1080/17461391.2016.1188992

Pageaux, \& Gaveau, J. (2016). Studies using pharmacological blockade of muscle afferents provide new insights into the neurophysiology of perceived exertion. The Journal of Physiology, 594(18), 5049-5051. https://doi.org/10.1113/jp272585

Pageaux, \& Lepers, R. (2016, 2016-November-29). Fatigue Induced by Physical and Mental Exertion Increases Perception of Effort and Impairs Subsequent Endurance Performance [Mini Review]. Frontiers in Physiology, 7(587). https://doi.org/10.3389/fphys.2016.00587 
Pageaux, \& Lepers, R. (2018). The effects of mental fatigue on sport-related performance. Prog Brain Res, 240, 291-315. https://doi.org/10.1016/bs.pbr.2018.10.004

Pageaux, Marcora, S., \& Lepers, R. (2013). Prolonged mental exertion does not alter neuromuscular function of the knee extensors. Medicine \& Science in Sports \& Exercise.

Preston, J., \& Wegner, D. M. (2009). Elbow grease: when action feels like work. In O. U. Press (Ed.), Oxford handbook of human action (pp. 569-586).

Preston, W. (2009). Elbow Grease: When Action Feels like work. 569-586.

Richter, M., Gendolla, G. H. E., \& Wright, R. A. (2016). Three Decades of Research on Motivational Intensity Theory. In (pp. 149-186). https://doi.org/10.1016/bs.adms.2016.02.001

Robert, H., Casillas, J. M., Iskandar, M., D'Athis, P., Antoine, D., Taha, S., Didier, V., Scaglioni, G., Caillaux, B. X., \& Van Hoecke, J. (2004, 2004/10/01/). Le Score d'activité physique de Dijon : reproductibilité et corrélations avec l'aptitude physique de sujets sains âgés. Annales de Réadaptation et de Médecine Physique, 47(8), 546-554. https://doi.org/https://doi.org/10.1016/j.annrmp.2004.03.005

Sacheli, M. A., Neva, J. L., Lakhani, B., Murray, D. K., Vafai, N., Shahinfard, E., English, C., McCormick, S., Dinelle, K., Neilson, N., McKenzie, J., Schulzer, M., McKenzie, D. C., Appel-Cresswell, S., McKeown, M. J., Boyd, L. A., Sossi, V., \& Stoessl, A. J. (2019, Dec). Exercise increases caudate dopamine release and ventral striatal activation in Parkinson's disease. Mov Disord, 34(12), 1891-1900. https://doi.org/10.1002/mds.27865

Seed, J. D., St. Peters, B., Power, G. A., \& Millar, P. J. (2019). Cardiovascular responses during isometric exercise following lengthening and shortening contractions. Journal of Applied Physiology, 126(2), 278-285.

Shadmehr, R., Huang, Helen J., \& Ahmed, Alaa A. (2016, 2016/07/25/). A Representation of Effort in Decision-Making and Motor Control. Current Biology, 26(14), 1929-1934. https://doi.org/https://doi.org/10.1016/j.cub.2016.05.065

Shahar, R. B., Kizony, R., \& Nota, A. (1998). Validity of the Purdue Pegboard Test in assessing patients after traumatic hand injury. Work, 11(3), 315-320. https://doi.org/10.3233/wor-1998$\underline{11308}$ 
1264

1265

1266

1267

1268

1269

1270

1271

1272

1273

1274

1275

1276

1277

1278

1279

1280

1281

1282

1283

1284

1285

1286

1287

1288

1289

1290

1291

1292

1293

1294

1295

1296

1297
Sidhu, S. K., Cresswell, A. G., \& Carroll, T. J. (2013, 2013/06/01). Corticospinal Responses to Sustained Locomotor Exercises: Moving Beyond Single-Joint Studies of Central Fatigue. Sports Medicine, 43(6), 437-449. https://doi.org/10.1007/s40279-013-0020-6

Smirmaul, B. P. C. (2014). Feedback from group III/IV muscle afferents is not the sensory signal for perception of effort. Experimental physiology, 99(5), 835-835.

Steele, J., \& Fisher, J. (2018). Effort, discomfort, group III/IV afferents, bioenergetics, and motor unit recruitment. Medicine \& Science in Sports \& Exercise, 50(8), 1718.

Thoroughman, K. A., \& Shadmehr, R. (1999, Oct 1). Electromyographic correlates of learning an internal model of reaching movements. J Neurosci, 19(19), 8573-8588.

https://doi.org/10.1523/jneurosci.19-19-08573.1999

Wang, J., Lum, P. S., Shadmehr, R., \& Lee, S. W. (2021). Perceived effort affects choice of limb and reaction time of movements. Journal of Neurophysiology, 125(1), 63-73. https://doi.org/10.1152/jn.00404.2020

Yang, C., Leitkam, S., \& Côté, J. (2019, 12/31). Effects of different fatigue locations on upper body kinematics and inter-joint coordination in a repetitive pointing task. PLOS ONE, 14, e0227247. https://doi.org/10.1371/journal.pone.0227247

Zinoubi, B., Zbidi, S., Vandewalle, H., Chamari, K., \& Driss, T. (2018). Relationships between rating of perceived exertion, heart rate and blood lactate during continuous and alternatedintensity cycling exercises. Biology of sport, 35(1), 29-37.

https://doi.org/10.5114/biolsport.2018.70749

Zourdos, M. C., Klemp, A., Dolan, C., Quiles, J. M., Schau, K. A., Jo, E., Helms, E., Esgro, B., Duncan, S., Garcia Merino, S., \& Blanco, R. (2016, Jan). Novel Resistance Training-Specific Rating of Perceived Exertion Scale Measuring Repetitions in Reserve. J Strength Cond Res, 30(1), 267-275. https://doi.org/10.1519/jsc.0000000000001049 